\title{
Tau accumulation in the retina promotes early neuronal dysfunction and precedes brain pathology in a mouse model of Alzheimer's disease
}

Marius Chiasseu', Luis Alarcon-Martinez ${ }^{1}$, Nicolas Belforte ${ }^{1}$, Heberto Quintero ${ }^{1}$, Florence Dotigny ${ }^{1}$, Laurie Destroismaisons ${ }^{1}$, Christine Vande Velde ${ }^{1}$, Fany Panayi ${ }^{2}$, Caroline Louis ${ }^{2}$ and Adriana Di Polo ${ }^{1 *}$ (D)

\begin{abstract}
Background: Tau is an axon-enriched protein that binds to and stabilizes microtubules, and hence plays a crucial role in neuronal function. In Alzheimer's disease (AD), pathological tau accumulation correlates with cognitive decline. Substantial visual deficits are found in individuals affected by AD including a preferential loss of retinal ganglion cells (RGCs), the neurons that convey visual information from the retina to the brain. At present, however, the mechanisms that underlie vision changes in these patients are poorly understood. Here, we asked whether tau plays a role in early retinal pathology and neuronal dysfunction in AD.
\end{abstract}

Methods: Alterations in tau protein and gene expression, phosphorylation, and localization were investigated by western blots, QPCR, and immunohistochemistry in the retina and visual pathways of triple transgenic mice (3xTg) harboring mutations in the genes encoding presenilin 1 (PS1M146 V), amyloid precursor protein (APPSwe), and tau (MAPTP301L). Anterograde axonal transport was assessed by intraocular injection of the cholera toxin beta subunit followed by quantification of tracer accumulation in the contralateral superior colliculus. RGC survival was analyzed on whole-mounted retinas using cell-specific markers. Reduction of tau expression was achieved following intravitreal injection of targeted siRNA.

Results: Our data demonstrate an age-related increase in endogenous retinal tau characterized by epitope-specific hypo- and hyper-phosphorylation in 3xTg mice. Retinal tau accumulation was observed as early as three months of age, prior to the reported onset of behavioral deficits, and preceded tau aggregation in the brain. Intriguingly, tau build up occurred in RGC soma and dendrites, while tau in RGC axons in the optic nerve was depleted. Tau phosphorylation changes and missorting correlated with substantial defects in anterograde axonal transport that preceded RGC death. Importantly, targeted siRNA-mediated knockdown of endogenous tau improved anterograde transport along RGC axons.

Conclusions: Our study reveals profound tau pathology in the visual system leading to early retinal neuron damage in a mouse model of AD. Importantly, we show that tau accumulation promotes anterograde axonal transport impairment in vivo, and identify this response as an early feature of neuronal dysfunction that precedes cell death in the AD retina. These findings provide the first proof-of-concept that a global strategy to reduce tau accumulation is beneficial to improve axonal transport and mitigate functional deficits in AD and tauopathies.

Keywords: Alzheimer's disease, Retinal ganglion cell, Tau, Axonal transport, Neurodegeneration

\footnotetext{
* Correspondence: adriana.di.polo@umontreal.ca

${ }^{1}$ Department of Neuroscience and Centre de recherche du centre hospitalier

de I'Université de Montréal (CRCHUM), Université de Montréal, 900 Rue

Saint-Denis, Tour Viger, Room R09.720, Montréal, QC H2X 0A9, Canada

Full list of author information is available at the end of the article
} 


\section{Background}

Tau, a member of the microtubule-associated protein family, plays a crucial role in many neurodegenerative diseases including Alzheimer's disease (AD), corticobasal dementia, frontotemporal lobar degeneration, progressive supranuclear palsy, and glaucoma [1-4]. These disorders share similar features including abnormal tau phosphorylation [5-7], protein aggregation [7, 8], neurofibrillary tangle formation $[9,10]$, and neurotoxicity $[4$, 11-13]. Tau dysfunction has been well described in AD, the principal cause of dementia worldwide [14, 15], and occurs several decades before the appearance of cognitive deficits $[16,17]$. At present, little is known about the early sequence of events leading to tau pathology in $\mathrm{AD}$, highlighting the need to elucidate the interplay of molecular and cellular changes during the pre-symptomatic stages of the disease.

The retina is an integral part of the central nervous system (CNS) and has long been considered a window to the brain. The signal produced by light-sensitive photoreceptors is transmitted to bipolar cells and then to retinal ganglion cells (RGCs), which send information via their axons in the optic nerve to visual centers in the brain [18]. As an integral part of the CNS, it is no surprise that the retina is affected by the same neurodegenerative processes that disturb brain function [19]. Indeed, visual deficits are common and significant in $A D$ [20]. Impaired contrast sensitivity, reduced visual acuity and abnormal motion perception are found in $\mathrm{AD}$, and these correlate tightly with the severity of cognitive and behavioral defects [21-31]. For example, $50 \%$ of AD patients presented with profound loss of pattern and spatial vision, including contrast sensitivity [32]. Approximately $50 \%$ of $\mathrm{AD}$ patients and $33 \%$ of individuals diagnosed with mild cognitive impairment have substantial visual motion perception deficits [33]. A study on individuals with AD-related senile dementia showed that $44 \%$ had important deficits in visual sensitivity measured by automated perimetry [34]. Morphological and additional functional impairments have also been described in the retina of $\mathrm{AD}$ individuals suffering from $\mathrm{AD}$ including preferential RGC loss and thinning of the retinal nerve fiber layer [35-38], abnormal electroretinogram response [39], and reduced blood flow [40, 41].

Similar to the brain, tau inclusions and amyloid beta $(\mathrm{A} \beta)$ deposition have been described in the retina of $\mathrm{AD}$ patients and in animal models of the disease [42-46]. Transgenic mice carrying the human P301S tau mutation contain tau aggregates in the retina [46], and display RGC functional deficits, increased susceptibility to excitotoxic damage, and altered neurotrophic factor signaling $[47,48]$. We recently reported key pathological changes of endogenous tau in glaucoma, an optic neuropathy characterized by selective RGC death and the leading cause of irreversible blindness worldwide [4]. Ocular hypertension, a major risk factor in glaucoma, triggered substantial tau changes reminiscent of AD including abnormal phosphorylation, missorting, and neurotoxicity [4]. Collectively, these findings suggest an association between tau alterations and retinal dysfunction, notably linked to RGC damage.

At present, a detailed characterization of the biochemical changes and cellular distribution of endogenous retinal tau and its impact on RGC function and survival during the early pre-symptomatic and prodromal stages of $\mathrm{AD}$ is lacking. To address this, we utilized the triple transgenic (3xTg) line [13]. The rationale for the choice of this AD mouse model was three-fold. First, the presence of mutations in the genes encoding presenilin 1 (PS1), amyloid precursor protein (APP), and tau (MAPT) have been identified as causing familial AD (PS1M146V, APPSWE) or tauopathies including frontotemporal dementia and parkinsonism linked to chromosome 17 (MAPTP301L) [49]. Second, unlike other models, the $3 x T g$ mice develop the two cardinal features of $\mathrm{AD}$, namely accumulation of $A \beta$ plaques and neurofibrillary tangles composed of tau, thus phenocopying critical pathological aspects of the disease [13]. Third, the $3 \times \mathrm{Tg}$ mice have been well-characterized regarding the appearance of brain lesions and cognitive deficits, thus providing a timeframe for the characterization of pathological changes in the visual system. Our data demonstrate that, as early as 3 months of age and prior to the onset of reported cognitive defects [50], abnormally phosphorylated tau accumulates in the retina of $3 x T g$ mice preceding its aggregation in the brain. Tau accumulation was primarily observed in RGC soma, dendrites and intraretinal axons, while tau in optic nerve axons was markedly reduced. Importantly, tau phosphorylation and missorting resulted in striking defects in anterograde axonal transport and age-dependent RGC neurodegeneration. Our study identifies novel alterations of endogenous retinal tau protein and neuronal dysfunction in the early stages of $\mathrm{AD}$, thus offering the possibility of exploiting tau to modulate disease susceptibility and onset.

\section{Methods}

\section{Experimental animals}

The $3 x \operatorname{Tg}$ mice bearing the human mutations in the genes encoding presenilin 1 (PS1M146V), amyloid precursor protein (APPSwe), and tau (MAPTP301L) [51], tau knockout mice (strain Mapt-tm1[EGFP]Klt/J), and age-matched littermate wild-type controls were purchased from Jackson Laboratories (Bar Harbor, ME) and maintained in our animal facility. Experiments were performed using 3 or 6 month-old female mice because they exhibit a more severe disease phenotype than their age-matched male counterparts [52]. All animal procedures were approved 
by the Centre de Recherche du Centre Hospitalier de l'Université de Montréal (CRCHUM) Animal Care Committee (approved protocol \#N14024ADPs), and followed the guidelines of the Canadian Council on Animal Care.

\section{Western blot analyses}

Whole retinas, optic nerves or brains (frontal cortex and hippocampus) were isolated and homogenized in icecold lysis buffer: $50 \mathrm{mM}$ Tris pH 7.4, $1 \mathrm{mM}$ EDTA, $150 \mathrm{mM} \mathrm{NaCl}, 1 \% \mathrm{NP}-40,5 \mathrm{mM}$ Na fluoride, $0.25 \% \mathrm{Na}$ deoxycholate, and $2 \mathrm{mM} \mathrm{NaVO}$ supplemented with protease and phosphatase inhibitors. Protein homogenates were centrifuged at $18,000 \mathrm{~g}$ for $5 \mathrm{~min}$, and the supernatants were removed and resedimented to yield soluble extracts. Samples in Laemmli buffer were boiled for $5 \mathrm{~min}$, resolved in 4-15\% SDS polyacrylamide gradient gels (Bio-Rad Life Science, Mississauga, ON), and transferred onto nitrocellulose membranes (Bio-Rad Life Science). Blots were incubated in blocking solution (10 mM Tris pH 8.0, $150 \mathrm{mM} \mathrm{NaCl}, 0.1 \%$ Tween-20 and $5 \%$ milk) for $1 \mathrm{~h}$ at room temperature, followed by overnight incubation at $4{ }^{\circ} \mathrm{C}$ with each of the following primary antibodies: total tau (K9JA, $1 \mu \mathrm{g} / \mathrm{ml}$, Dako North America, Carpinteria, CA), phospho-tau S396S404 (PHF1, 1:100, gift of P. Davies, Albert Einstein College of Medicine, Bronx, NY), phospho-tau S199 (PS199, $1 \mu \mathrm{g} / \mathrm{ml}$, Invitrogen, Burlington, ON), phosphotau S202-T205 (AT8, $0.8 \mu \mathrm{g} / \mathrm{ml}$, Thermo-Fisher Scientific, Waltham, MA), MC-1 (1:100, gift of P. Davies), ALZ-50 (1:100, gift of P. Davies), or $\beta$-actin $(0.5 \mu \mathrm{g} / \mathrm{ml}$, SigmaAldrich, Oakville, ON). Membranes were washed and incubated in peroxidase-linked donkey anti-mouse or donkey anti-rabbit antibodies $(0.5 \mu \mathrm{g} / \mathrm{ml}$, GE Healthcare, Mississauga, ON). Blots were developed with a chemiluminescence reagent (ECL, Amersham Biosciences, Arlington Heights, IL) and exposed to X-OMAT imaging film (Eastman Kodak, Rochester, NY). Densitometry was performed on scanned autoradiographic films using the ImageJ software (http://imagej.nih.gov/ij/). Films were obtained from at least three independent western blots each carried out using retinal samples from different groups.

\section{Retina and optic nerve immunohistochemistry}

Animals were perfused with $4 \%$ paraformaldehyde and the eyes and optic nerves were rapidly dissected. Tissue was embedded in optimal cutting temperature compound (Tissue-Tek, Miles Laboratories, Elkhart, IN), and retinal $(16 \mu \mathrm{m})$ or optic nerve $(12 \mu \mathrm{m})$ cryosections were collected onto Superfrost Plus microscope slides (Thermo-Fisher Scientific). The following primary antibodies were added to retinal or optic nerve sections in blocking solution and incubated overnight at $4{ }^{\circ} \mathrm{C}$ as described [53]: total tau (K9JA, $2 \mu \mathrm{g} / \mathrm{ml}$, Dako), tubulin isoform $\beta$ III (TUJ1, $2.5 \mu \mathrm{g} / \mathrm{ml}$; Sigma-Aldrich), or neurofilament $\mathrm{H}(\mathrm{NF}-\mathrm{H}, 20 \mu \mathrm{g} / \mathrm{ml}$, Sternberger Monoclonals Inc., Lutherville, MA). For whole-mounted retinas, tissue was permeabilized overnight at $4{ }^{\circ} \mathrm{C}$ in blocking solution, rinsed and incubated for 5 days at $4{ }^{\circ} \mathrm{C}$ in the following primary antibodies: total tau (K9JA, $2 \mu \mathrm{g} /$ ml, Dako), RNA-binding protein with multiple splicing (RBPMS, 1:1000, PhosphoSolutions, Aurora, CO), or NF-H $(20 \mu \mathrm{g} / \mathrm{ml}$, Sternberger Monoclonals Inc.). Sections or whole retinas were washed and incubated with secondary donkey anti-rabbit or anti-mouse Alexa Fluor 594 and $488(2 \mu \mathrm{g} / \mathrm{ml}$, Life Technologies, Eugene, OR). Fluorescent labeling was observed using a Zeiss Axio Observer (Carl Zeiss, Canada) or a Leica SP5 confocal microscope (Leica Microsystems Inc., Concord, ON). All retinal and optic nerve images were acquired under identical conditions using the same illumination intensity, time exposure, and magnification, with careful attention to avoid signal saturation and/or bleaching. The areas sampled were selected using an unbiased stereological sampling method as described (http://www.stereology.info).

\section{Reverse transcription and quantitative real time PCR (qPCR)}

Total RNA was isolated from individual retinas using the RNEasy Mini kit (Qiagen Inc., Valencia, CA). cDNAs were generated from $1 \mu \mathrm{g}$ of total RNA using the QuantiTect Reverse Transcription Kit (Qiagen Inc.). Real-time PCR was performed using TaqMan probes and primers that target exon 5, expressed by all tau isoforms (pantau, catalog \# Rn01495715), exon 4a specific to big tau (catalog \# Rn01495711), or $\beta$-actin RNA as control (catalog \# 4331182) (Applied Biosystems, Waltham, MA). Amplification was performed using the $7900 \mathrm{HT}$ Fast Real-Time PCR System (Applied Biosystems) with the following cycle conditions: $95^{\circ} \mathrm{C}$ for $15 \mathrm{~s}, 60{ }^{\circ} \mathrm{C}$ for $1 \mathrm{~min}, 72{ }^{\circ} \mathrm{C}$ for $1 \mathrm{~min}$. Reactions were run in triplicates for each sample and the $2^{-\Delta \Delta} \mathrm{Ct}$ formula was used for the calculation of differential gene expression.

\section{Axonal transport measurement}

Anterograde axonal transport was assessed by injection of cholera toxin $\beta$ subunit (CT $\beta$ ) conjugated to Alexa Fluor 488 (Molecular Probes, Life Technologies, Eugene OR) as described previously $[54,55]$. CT $\beta$ is a reliable marker of active transport and has been consistently used to assess RGC anterograde transport to the superior colliculus $[56,57]$. CT $\beta$ ( $1 \%$ diluted in sterile PBS, total volume: $1 \mu \mathrm{l}$ ) was injected intravitreally using a custom-made sharpened microneedle generated from a borosilicate glass capillary tube $(5 \mu \mathrm{l}$, World Precision Instruments, Sarasota, FL) as previously described by us [58]. Briefly, the glass capillary was pulled using a two stage needle puller (PC-10, Narishige International, 
Amityville, NY) to produce thin microneedles of $6 \mathrm{~cm}$ in length. Under a dissecting microscope, a sharp blade was used to carefully create an opening at the tip of the microneedle. The resulting opening had an elliptical shape with a major and minor axis diameter of approximately $190 \mu \mathrm{m}$ and $70 \mu \mathrm{m}$, respectively. The tip of the microneedle was then beveled using a micropipette bevelling system until the tip was sharp and the edges were flat and smooth [58]. For intravitreal injections, animals were anesthetized with isoflurane $(2 \%, 0.8 \mathrm{~L} / \mathrm{min})$. The upper eyelid was gently retracted and the tip of the glass microneedle positioned at a $45^{\circ}$ angle relative to the ocular surface. A light pressure was exerted to insert the microneedle through the conjunctiva, sclera and retina into the vitreous cavity. The tracer was injected and the needle was retracted slowly to avoid reflux. This route of administration avoided injury to ocular structures, including the iris and the lens. A small drop of antibiotic was applied topically after the surgery (Vigamox, 0.5\%, Alcon Canada Inc., Mississauga, ON), and there were no signs of post-operative infection or inflammation. Animals were perfused transcardially with $4 \%$ paraformaldehyde three days after CT $\beta$ administration; brains were removed and embedded in optimal cutting temperature compound (Tissue-Tek, Miles Laboratories). Serial coronal cryosections of the entire superior colliculus from each animal were obtained using a cryostat $(50-\mu \mathrm{m}$ thickness). Seven sections per superior colliculus, from rostral to caudal, were selected using an unbiased stereological sampling method. Sections were photographed digitally using the Zeiss Axio Observer fluorescent microscope with Apotome (Carl Zeiss) and the area of the CT $\beta$ signal in each section was measured using the Imaris MeasurementPro module (Bitplane, South Windsor, CT). The total CT $\beta$ signal in each superior colliculus was calculated using the formula: total CT $\beta$ area $=\Sigma$ CT $\beta$ section area/ssf $\mathrm{x}$ asf $\mathrm{x}$ tsf [59]. The section sampling fraction (ssf) was the number of sections analyzed over the total number of sections obtained from each superior colliculus (7/36), the area sampling fraction (asf) was the area sampled divided by the total area (1), and the thickness sampling fraction (tsf) was the section thickness sampled divided by the total section thickness (1). This analysis provided a representative value of CT $\beta$ positive area which was then multiplied by the width of the entire superior colliculus to yield the total CT $\beta$ volume. To confirm CT $\beta$ uptake by RGCs, whole retinas were incubated overnight at $4{ }^{\circ} \mathrm{C}$ with goat IgG against the RGC-specific marker brain-specific homeobox/POU domain protein 3a (Brn3a, $0.27 \mu \mathrm{g} / \mathrm{ml}$, Santa Cruz Biotechnology, Santa Cruz, CA) followed by secondary Alexa Fluor 594 anti-goat IgG $(1 \mu \mathrm{g} / \mathrm{ml}$; Jackson ImmunoResearch Laboratories, West Grove, PA). Retinas were rinsed, mounted, and the total number of CT $\beta$-positive and Brn3a-positive neurons was quantified by independent random stereological sampling.

\section{Intravitreal injections of short interfering RNA (siRNA)}

The following siRNA sequences against Tau (siTau) were purchased: i) 5'-CCUAGAAAUUCC AUGACGA-3', ii) 5' -GGACAGGAAAUGACGAGAA-3' iii) 5'-GCUGAU AGGCAGUUUAC AA-3', iv) 5'-UGGGUGGGCUAGAU AGAUA-3' (ON-TARGETplus mouse Mapt siRNASMART pool, GE Dharmacon, Lafayette, CO). The following control siRNA (siCtl) sequence was used: 5'-UG GUUUACAUGUUGUGUGA-3' (ON-TARGETplus, nontargeting siRNA \#2, GE Dharmacon). Each siRNA was injected into the vitreous chamber using a custom-made sharpened glass microneedle as described above $(3.8 \mu \mathrm{g} / \mu \mathrm{l}$, total volume: $2 \mu \mathrm{l})$.

\section{Quantification of RGC soma}

Mice were subjected to transcardial perfusion with $4 \%$ paraformaldehyde and retinas were dissected out and fixed for an additional $15 \mathrm{~min}$. Free-floating retinas were blocked overnight at $4{ }^{\circ} \mathrm{C}$ in $10 \%$ normal goat serum, $2 \%$ bovine serum albumin, $0.5 \%$ Triton X-100 in PBS, and incubated with the RGC-specific marker RBPMS (1:1000, PhosphoSolutions) for 5 days at $4{ }^{\circ} \mathrm{C}$. Retinas were then incubated with Alexa 594-coupled secondary antibody $(2 \mu \mathrm{g} / \mathrm{ml}$, Life Technologies) for $4 \mathrm{~h}$ at room temperature, washed, mounted with the nerve fiber layer side up, and visualized with a Zeiss Axio Observer (Carl Zeiss). RBPMS-labeled RGCs were counted within three square areas at distances of $0.25,0.625$ and $1 \mathrm{~mm}$ from the optic disc in each of the four retinal quadrants for a total of twelve retinal areas as described by us [4].

\section{Statistical analyses}

Data analysis and statistics were performed using GraphPad Instat software (GraphPad Software Inc., San Diego, CA) by a Student's $t$-test as indicated in the legends.

\section{Results}

Tau protein accumulation in the retina precedes build up in the brain

Visual deficits and pathological changes have been described in the retinas of AD patients [21,31]. Therefore, we first asked whether the level of endogenous retinal tau was altered in 3xTg mice and, if so, whether it correlated with tau changes in the brain. For this purpose, retinal and brain protein samples from 3- and 6-month-old 3xTg mice were analyzed and compared to those from agematched wild-type controls. These time points were selected because they precede the appearance of reported behavioral and cognitive defects in this model $[50,60]$. Western blots of soluble retinal homogenates using an antibody against total tau (K9JA), which binds the 
microtubule binding domain of the protein irrespective of its phosphorylation state $[61,62]$, revealed the presence of four predominant tau isoforms of $37-\mathrm{kDa}, 50-\mathrm{kDa}, 55-$ $\mathrm{kDa}$ and $100-\mathrm{kDa}$ (Fig. 1a). The 100-kDa band most likely corresponded to big tau, a high molecular weight tau isoform detected only in retinal and peripheral neurons [63-65]. Densitometry analysis showed that all four tau isoforms increased in 3-month-old 3xTg mouse retinas relative to age-matched wild-type controls (Fig. 1c). Analysis of cortical and hippocampal homogenates revealed the presence of four tau isoforms of $37-\mathrm{kDa}$ $50-\mathrm{kDa}, 55-\mathrm{kDa}$, and $60-\mathrm{kDa}$ (Fig. 1b). In contrast to retina, however, the levels of all brain tau isoforms in 3 -month-old 3xTg mice were similar to those in agematched controls (Fig. 1d). No signal was detected in retinal or brain samples from tau null mice thus confirming the specificity of the K9JA antibody in these tissues (Fig. 1a, b). Western blot and densitometry analyses revealed an increase of the $55-\mathrm{kDa}$ tau isoform in both retina and brain samples from of 6-month-old 3xTg mice, while all other isoforms remained unchanged (Fig. 1e-h). These results demonstrate that tau protein increases in transgenic retinas early in the disease process and precedes tau accumulation in the brain.

\section{Retinal tau undergoes epitope-specific and age- dependent phosphorylation changes in $A D$}

Alterations in tau phosphorylation contribute to tau dysfunction in pathological conditions [14, 66, 67]. Therefore, we analyzed tau phosphorylation in retinal samples from $3 x \operatorname{Tg}$ mice using the phospho-tau specific antibodies AT8 (S202, T205) [68, 69], PS199 (S199) [70], and PHF1 (S396, S404) [71, 72]. These antibodies were selected because they recognize phospho-specific epitopes that correlate with AD severity [73]. Visualization of western blots probed with AT8 or PHF1 revealed an increase in tau phosphorylation at these epitopes in 3-month-old 3xTg retinas (Fig. 2a, b). Densitometry analysis of phospho-tau signals with respect to total tau, which markedly increased at this age, confirmed greater tau phosphorylation on residues S202 and T205 of all isoforms (AT8, Fig. 2a, d), while a relative decrease at residue S199 was observed (PS199: 55-kDa, 100-kDa) (Fig. 2b, e). Conversely, 6-month-old 3xTg retinas displayed reduced phosphorylation with AT8 on all isoforms (Fig. 2g, j), and increased phosphorylation with PS199 (50-kDa, 55-kDa, 100-kDa) (Fig. 2h, k). No significant changes were detected with PHF1 in 3- or 6-month-old 3xTg retinas relative to controls (Fig. 2c-l).

Phosphorylation can lead to changes in the conformation of tau protein during the course of $\mathrm{AD}$, which can play a key role in pathological tau accumulation and cleavage $[74,75]$. The conformation of tau in $3 x T g$ retinas was investigated using the antibodies MC-1 and
ALZ-50, which recognize the early folding back of the $\mathrm{N}$-terminus on the microtubule domain in a hairclip configuration linked with tau aggregation [74, 76, 77]. No changes in conformation-dependent epitopes recognized by $\mathrm{MC}-1$ or ALZ-50 were detected in 3- or 6-month-old 3xTg retinas relative to age-matched controls (Fig. 3). Together, these data demonstrate increased tau phosphorylation at AT8 epitopes in the early presymptomatic stages, whereas increased phosphorylation at PS199 appears at a later phase of the disease, in the absence of conformational changes. We conclude that retinal tau undergoes complex age-related and epitopespecific changes in $\mathrm{AD}$.

\section{Tau accumulates in the RGC somatodendritic compartment and intraretinal axons}

The cellular distribution of tau in the retina was investigated by immunohistochemistry using the K9JA antibody against total tau. In agreement with previous reports [4, 78], a low basal level of tau expression was found in all retinal layers except the outer nuclear layer (Fig. 4a, c). Consistent with our biochemical findings, retinal tau increased in 3-and 6-month-old 3xTg mice and its accumulation was more pronounced in the inner plexiform layer (IPL), where RGC dendrites are located (Fig. 4b, d). Labeling with an antibody against tubulin isoform BIII (TUJ1), an RGC-specific marker that strongly labels the soma and dendrites of these neurons $[79,80]$, confirmed localization of tau within the somatodendritic compartment (Fig. 4e-g). Further analysis of tau distribution on flat-mounted retinas using RBPMS, which selectively labels RGC soma [81, 82], confirmed tau accumulation in RGC bodies in $3 \times \mathrm{Tg}$ retinas relative to controls (Fig. 4h-m). A similar distribution of tau was observed in 6-month-old transgenic mice, with more robust tau build up at this age (Fig. 4n-s).

Further analysis of tau expression in flat-mounted retinas, specifically changes in the intraretinal RGC axons, was investigated by co-localization of tau with the axonal marker neurofilament-H (NF-H). In wild-type retinas, low basal levels of tau protein were detected in RGC intraretinal axons, visualized with NF-H (Fig. 5a-c, g-i). In contrast, a pronounced increase of tau signal in NF$\mathrm{H}$-positive axons was detected in $3 \times \mathrm{Tg}$ retinas at both 3 and 6 months of age (Fig. $5 d-f, j-1)$. To establish whether tau accumulation in the retina resulted from increased gene expression, real-time $\mathrm{qPCR}$ was performed using primers that recognized all tau isoforms (pan-tau) or big tau [63-65]. No significant changes in tau mRNA levels were detected in $\mathrm{AD}$ retinas compared to controls (Fig. $5 \mathrm{~m}$ ). These data indicate that tau accrues early in the AD retina, predominantly in RGC dendrites and intraretinal axons, and that this accumulation is not the result of increased gene expression. 

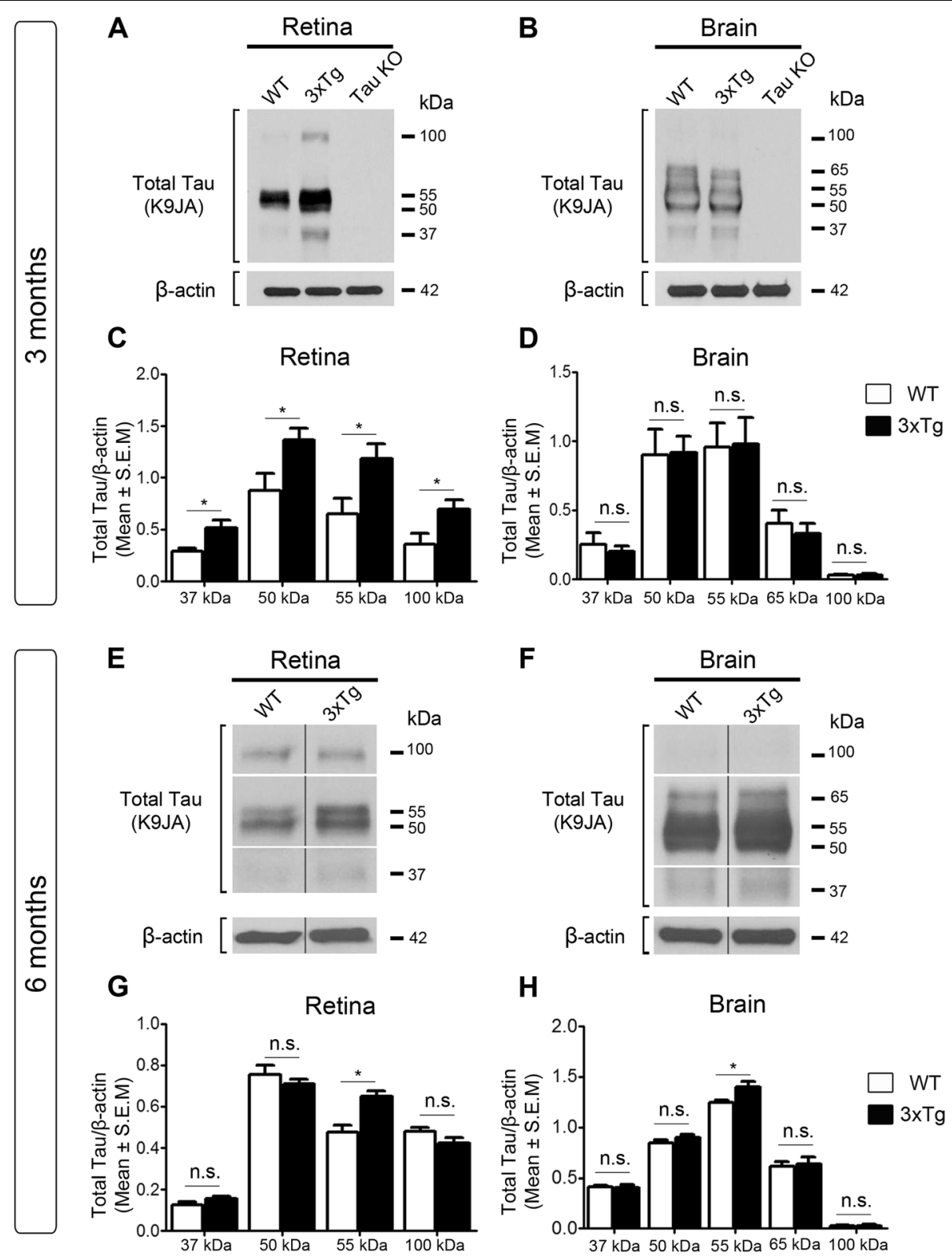

Fig. 1 Tau protein accrues in the retina and precedes accumulation in the brain. a Representative western blots of soluble retinal extracts from 3-month-old 3xTg mice and wild-type (WT) age-matched controls probed with an antibody against total tau (K9JA) revealed the presence of four tau isoforms: $37-\mathrm{kDa}$, $50-\mathrm{kDa}, 55-\mathrm{kDa}$ and $100-\mathrm{kDa}$. All retinal tau isoforms were detected in both wild-type and 3xTg retinas. No signal was detected in tau knockout mice validating the specificity of the K9JA antibody. $\mathbf{b}$ Western blot analysis of brain homogenates from 3-month-old 3xTg mice and age-matched controls revealed four isoforms of $37-\mathrm{kDa}, 50-\mathrm{kDa}, 55-\mathrm{kDa}$ and $65-\mathrm{kDa}$, while no signal was detected in brains from tau knockout mice. $\mathbf{c}$ Densitometry analysis showed a 1.8-, 1.6-, 2- and 2-fold increase in the 37-kDa, 50-kDa, 55-kDa, and 100-kDa tau variants, respectively, in retinal samples from 3xTg mice $(n=10)$ compared to WT controls $(n=8)$ (Student's $t$-test, $\left.{ }^{*}=p<0.05\right)$. d Quantitative analysis revealed no changes in brain tau levels between $3 \times \operatorname{Tg}$ mice $(n=10)$ and WT controls $(n=10)$ (Student's $t$-test, n.s.: not significant, $p>0.05)$. e, f Western blots using retinal (e) or brain (f) samples from 6-month-old 3XTg mice demonstrated that only the 55-kDa tau form increased relative to age-matched WT controls. $\mathbf{g}$, $\mathbf{h}$ Densitometry analysis indicated a 1.4-fold increase in the 55-kDa tau isoform in the retina ( $\mathbf{g})$ and brain $(\mathbf{h})$ of 3xTg mice compared to controls (3xTg: $n=5$, WT: $n=4$, Student's $t$-test, ${ }^{*}=p<0.05$ ). Vertical lines represent non-consecutive samples from the same gel

Tau is depleted from RGC axons in 3xTg optic nerves In normal physiological conditions, tau is enriched in axons with low levels found in dendrites and soma [83]. In $\mathrm{AD}$ and other tauopathies, tau detaches from axonal microtubules and accumulates in the somatodendritic compartment of affected neurons [84]. To assess whether the distribution of tau in RGC axons within the optic nerve was altered in $3 \mathrm{xTg}$ mice, we carried out 


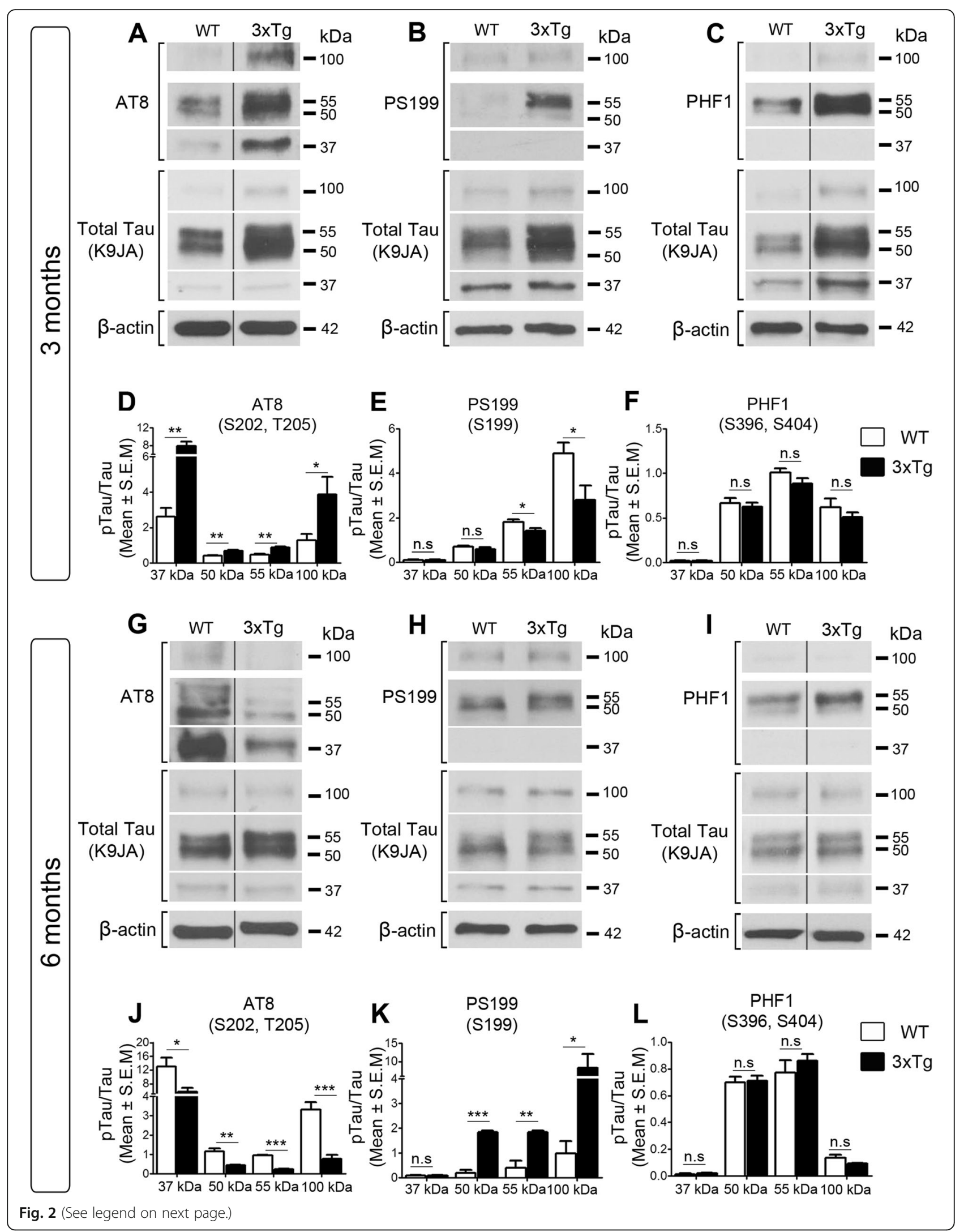




\section{(See figure on previous page.)}

Fig. 2 Retinal tau undergoes epitope-specific and age-dependent phosphorylation changes in AD. a-c Western blot analyses of retinal homogenates probed with the phospho-tau specific antibodies AT8, PS199, and PHF1 revealed alterations in tau phosphorylation in 3xTg relative to wild-type (WT) mice. d-f Densitometry analysis of phospho-tau relative to total tau revealed increased tau phosphorylation on S202/T205 (AT8) and reduced phospho-S199 (PS199) in 3xTg retinas relative to controls, while no change was detected on S396/S404 (PHF1) (3xTg: $n=5$, WT: $n=4$, Student's $t$-test, $\left.{ }^{*}=p<0.05,{ }^{* *}=p<0.01\right)$. $\mathbf{g}$-i Western blot analysis of tau phosphorylation in 6-month-old 3xTg retinas showed alterations on epitopes AT8 and PS199, but not PHF1, relative to controls. j-I Quantitative analysis confirmed decreased tau phosphorylation on S202/T205, increased phosphorylation on S199, and no change on PHF1 (3xTg: $n=5, \mathrm{WT}: n=4$, Student's t-test, ${ }^{*}=p<0.05,{ }^{* *}=p<0.01,{ }^{* * *}=p<0.001$, n.s.: not significant $p>0.05$ ). Vertical lines represent non-consecutive samples from the same gel

confocal imaging of nerve cross sections colabeled with tau and the axonal marker NF-H. In control optic nerves, tau was enriched in RGC axons visualized with $\mathrm{NF}-\mathrm{H}$ (Fig. 6a-c, m-o). In contrast, 3xTg optic nerves from both 3- and 6-month-old mice displayed a striking reduction in axonal tau protein (Fig. $6 g-i, s-u$ ). High magnification confocal images of individual optic nerve fascicles revealed that many NF-H positive axons were still detected in transgenic animals in spite of marked reduction of tau protein levels (Fig. 6j-l, v-x), indicating that a decrease in tau was not the result of axonal degeneration. Western blot analysis of optic nerve homogenates confirmed a visible reduction of tau protein in 3- and 6-month-old 3xTg mice (Fig. 6y, Y', z, Z'). Taken together, our results demonstrate that tau is markedly reduced in RGC axons within the optic nerve early in the course of the disease.

\section{Anterograde transport impairment in 3xTg RGCs precedes neuronal death}

RGCs, like other long projecting neurons, rely heavily on axonal transport for proper function. Anterograde transport impairment is recognized as an early sign of RGC damage and dysfunction [55]. Therefore, we examined whether the ability of RGCs to transport the anterograde tracer CT $\beta$ to terminals in the superior colliculus, the primary target of RGCs in the rodent brain [85-87], was altered in $3 x \mathrm{xg}$ mice. CT $\beta$ is an excellent reagent to study axonal transport because of its high sensitivity, ability to effectively move anterogradely or retrogradely from the injection site, dependency on intact microtubules thus serving as readout of active transport, capacity to label the entire neuron including extremely fine terminals, restriction from labeling fibers of passage, and demonstrated efficacy to label axonal tracts in the visual system following ocular administration [54-56, 88-96]. Alexa Fluor 488-conjugated CT $\beta$ was injected intravitreally and its accumulation in the contralateral superior colliculus was quantified using unbiased stereological sampling [54]. Mutant APP, PS1 and tau proteins are expressed throughout development in $3 x \mathrm{Tg}$ mice, thus we first aimed to establish whether there were developmental alterations in axonal transport in young mice (21 days), a week after eye opening. Our data demonstrate that there was no difference in the amount of brain CT $\beta$ between wild-type and $3 \times \mathrm{Tg}$ at 21 days of age (Fig. 7a, b). In contrast, a substantial reduction in the CT $\beta$-labeled volume was observed in 3and 6-month-old 3xTg mice relative to age-matched controls (Fig. 7c-f). Quantification of total CT $\beta$ volume confirmed a $57 \%$ reduction in the superior colliculi of $3 x T g$ mice suggesting major deficits in the ability of RGCs to transport cargos to their targets (Fig. 7g). These findings indicate that deficits in anterograde axonal transport in $3 \times \mathrm{Tg}$ mice are not of developmental origin, but rather reflect pathological changes detected early in the course of the disease.

To rule out that anterograde transport deficits were caused by the inability of 3xTg RGCs to uptake CT $\beta$, we examined CT $\beta$-injected retinas with Brn3a, a selective marker of RGC nuclei [97]. Abundant cytoplasmic CT $\beta$ within RGCs was observed at $24 \mathrm{~h}$ after tracer injection in both wild-type and transgenic retinas (Fig. 7h, i). Quantification of Brn3a-positive RGCs containing CT $\beta$ revealed a similar number of neurons in both $3 \times \mathrm{Tg}$ and control mice (Fig. 7j), thus confirming effective tracer uptake. To determine whether anterograde transport deficits reflected neuronal death, RGC density was quantified in 3- and 6-month-old transgenic retinas using the cell-specific marker RBPMS. A similar RGC density was found in $3 \times \mathrm{Tg}$ and wild-type mice at 3 months of age, confirming the absence of significant cell death at a time when major transport deficits are already apparent (Fig. $7 \mathrm{k}-0$ ). In 6-month-old transgenic retinas, only a modest reduction in RGC density was detected relative to controls ( 15\%, Fig. $7 \mathrm{~m}-\mathrm{o})$, therefore the substantial axonal transport loss at this age cannot be ascribed solely to retinal neuron death. Collectively, these results demonstrate that major deficits in axonal transport along RGC axons are a relatively early feature of neuronal dysfunction in $\mathrm{AD}$ pathology that precedes cell death.

\section{Selective tau knockdown improves RGC axonal transport}

To investigate whether tau accumulation underlies the axonal transport deficits in 3xTg RGCs, we sought to decrease tau protein levels using siRNA followed by analysis of CT $\beta$ transport. First, we assessed the ability of a targeted siRNA against tau (siTau) to reduce retinal tau 


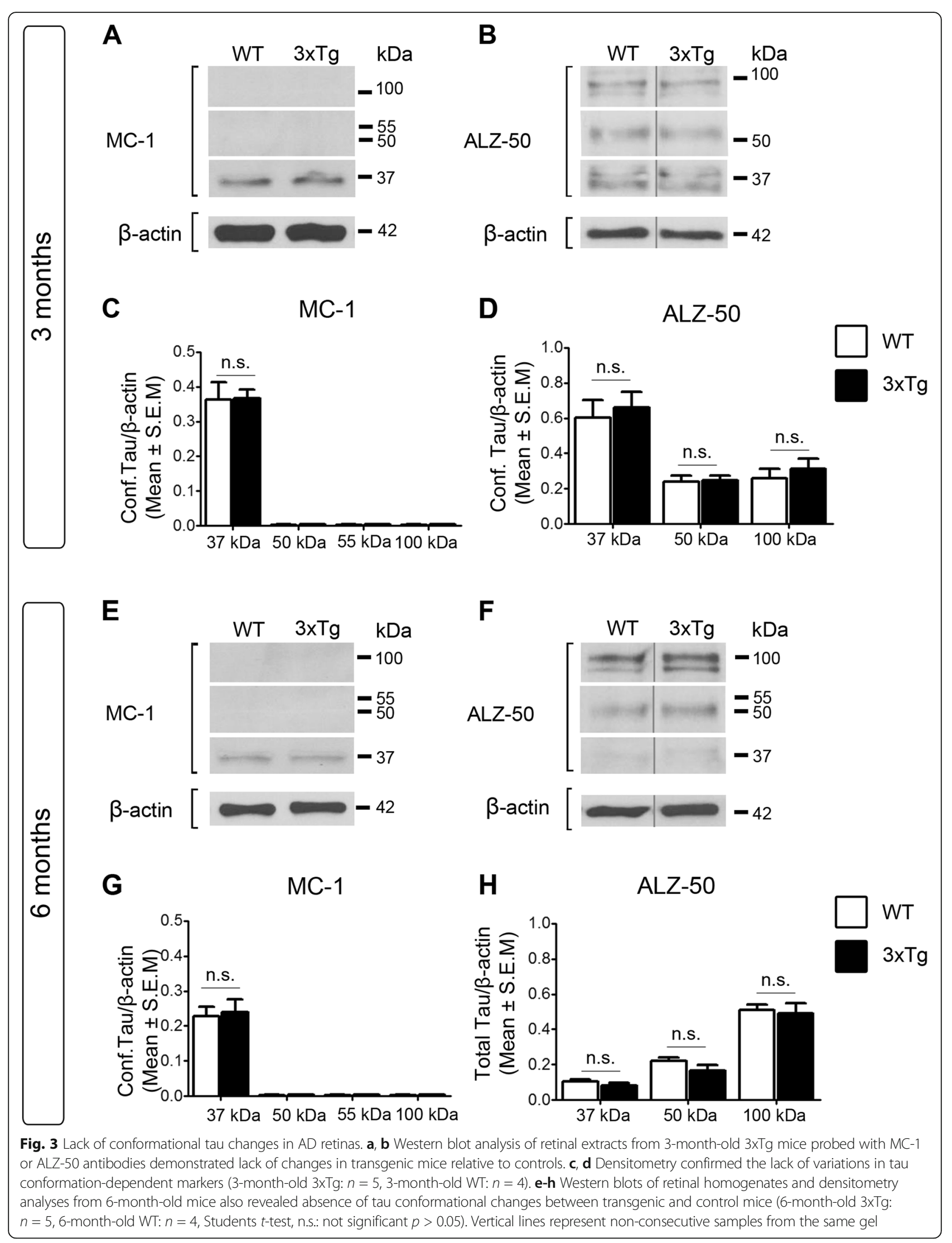




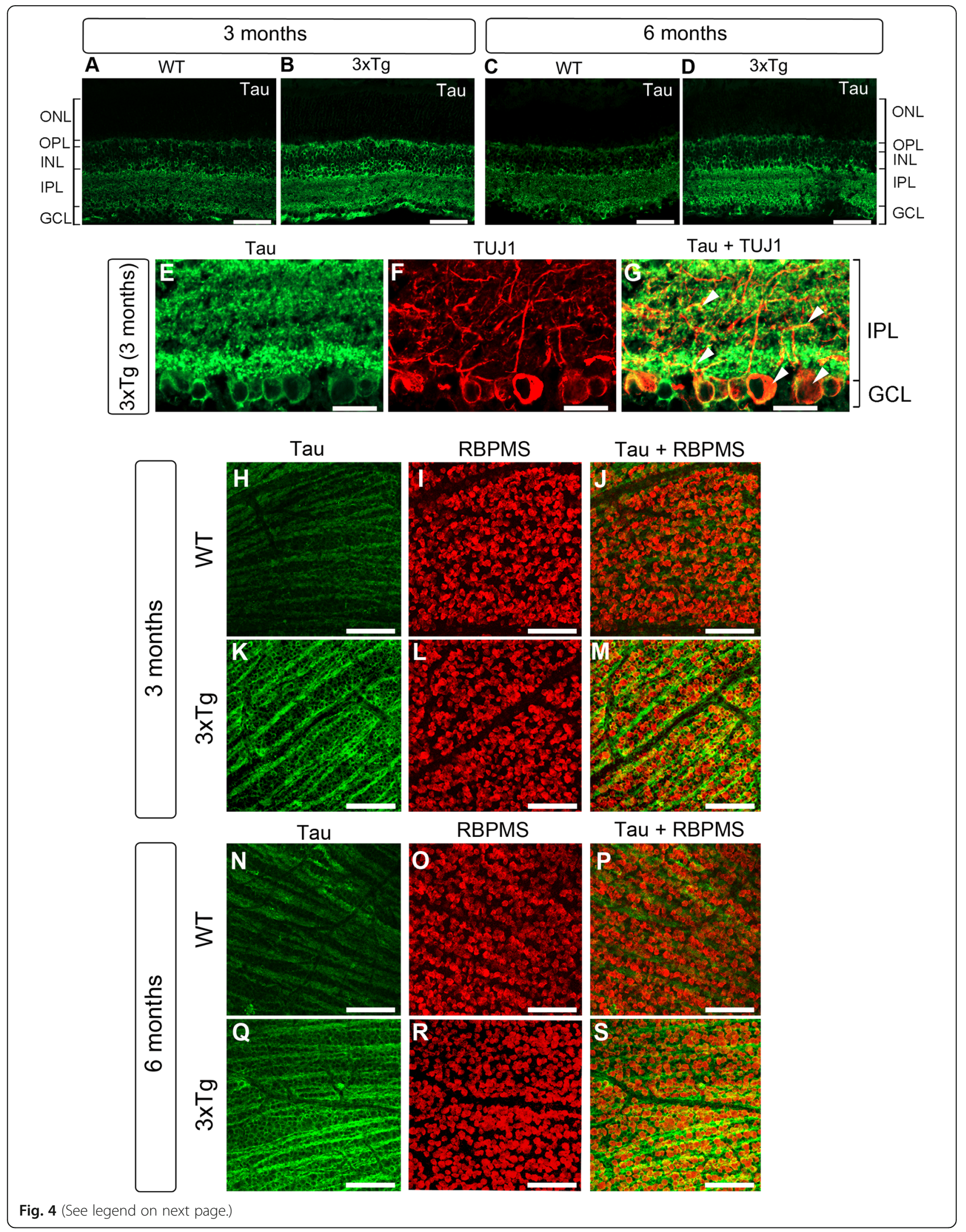


(See figure on previous page.)

Fig. 4 Tau accumulates in the somatodendritic compartment of RGCs. a-d Retinal immunohistochemistry using antibodies against total tau (K9JA) revealed marked tau upregulation in 3- and 6-month-old 3xTg retinas relative to age-matched wild-type (WT) controls. e-g Co-staining of tau with TUJ1, an RGC-specific marker, demonstrated tau accumulation in 3xTg RGC dendrites and somata (arrowheads) ( $n=5 / g r o u p)$. h-s Whole-mount retinal preparations from 3- and 6-month-old mice show co-localization of tau and RBPMS, a selective marker of RGC soma, demonstrating age-dependent accumulation of tau in RGC soma ( $n=5 /$ group). Scale bars: A-D $=50 \mu \mathrm{m}, \mathrm{E}-\mathrm{G}=25 \mu \mathrm{m}, \mathrm{H}-\mathrm{S}=50 \mu \mathrm{m}$. ONL: outer nuclear layer, OPL: outer plexiform layer, INL: inner nuclear layer, IPL: inner plexiform layer, GCL: ganglion cell layer

protein levels. We previously demonstrated that siRNA delivered by intravitreal injection is rapidly taken up by RGCs [98]. Western blot analysis of retinal extracts from 3-month-old 3xTg eyes that received siTau showed a significant reduction in tau protein relative to age-matched transgenic mice that received a control non-targeting siRNA (siCtl) (Fig. 8a). Quantitative analysis confirmed that siTau induced a $27 \%, 42 \%$ and $50 \%$ reduction of the $50-\mathrm{kDa}, 55-\mathrm{kDa}$ and $100-\mathrm{kDa}$ tau isoforms, respectively, relative to control siRNA-treated eyes (Fig. 8b). Next, we investigated whether siRNA-mediated tau knockdown improved RGC axonal transport. For this purpose, siTau was injected intraocularly once a week for a total of three weeks. The multiple injection regimen was selected based on our previous findings that siRNAmediated protein knockdown in the retina is transient [98]. Four days after the last siTau injection, СT $\beta$ was administered in the eye and the amount of the tracer in the superior colliculus quantified three days later. Visualization of caudal-to-rostral sections from the superior colliculus of siTau-treated 3xTg mice showed a marked increase in CT $\beta$ relative to transgenic mice that received control siCtl (Fig. 8c, d). Quantitative analysis confirmed that tau knockdown promoted a significant increase in anterograde axonal transport compared to control animals (20\%, Fig. 8e). Our results demonstrate that attenuation of retinal tau levels improves axonal transport, suggesting that early tau accumulation in the retina impairs axonal function in $\mathrm{AD}$.

\section{Discussion}

Data presented here in a well-characterized mouse model of $\mathrm{AD}$ reveal profound alterations in tau within the retina and the visual pathways leading to neuronal dysfunction in vivo. First, we demonstrate that retinal tau accumulation in 3xTg mice occurs early and precedes pathological changes in the brain. Second, our data show that retinal tau undergoes age-related and epitope-specific changes in phosphorylation, which are independent of conformational modifications. Third, we found that tau build up occurs in the somatodendritic compartment and intraretinal axons of RGCs, whereas tau is depleted from optic nerve axons. Lastly, our results demonstrate that tau accumulation leads to substantial deficits in anterograde transport along $3 x \mathrm{Tg}$ RGC axons, and that tau knockdown improves axonal transport. Collectively, this study reveals early and profound alterations in retinal tau leading to axonal dysfunction suggesting a role for pathological tau in visual deficits associated with AD.

Accumulation of pathological tau is a hallmark of $\mathrm{AD}$ and other tauopathies $[1,66,99,100]$. Our data using the 3xTg mouse model, demonstrate early accumulation of tau in the retina prior to the onset of reported cognitive defects [50]. This finding is consistent with previous studies demonstrating increased retinal tau levels in murine models of tauopathies [45, 46, 48, 78]. The increase in retinal tau reported here was considerably more pronounced in younger mice than in older individuals. The expression of mutant tau in 3xTg mice is under the control of the Thy1 promoter [51], and Thy1 transcriptional activity has been shown to remain constant in the adult retina [81]. Therefore, it is unlikely that the marked age-dependent increase in retinal tau reported here is due to changes in Thy1 promoter activity. This is further supported by our finding that tau protein upregulation is not the result of increased gene expression. Instead, our results reveal a robust retinal response early in the course of the disease, suggesting that the imbalance in tau levels in younger individuals might increase the risk of neuronal dysfunction and subsequent neurodegeneration at later stages of the disease. We also demonstrate that tau accumulation in the retina precedes tau build up in the brain. Importantly, even in older mutant mice, which accrue tau in both retinas and brain, the relative increase of tau was consistently higher in retinal than brain samples. These results identify the retina as a highly sensitive system that reflects early tau protein accumulation in $\mathrm{AD}$.

Phosphorylation is a critical post-translational modification of tau during development and in pathological conditions [101]. Inclusions of phosphorylated tau are found in most tauopathies and correlate with severity of disease [73], however, virtually nothing is known about alterations in tau phosphorylation in the $\mathrm{AD}$ retina. We found that while tau residues S202 and T205 were highly phosphorylated (AT8), there was a net decrease in the phosphorylation of S199 relative to total tau levels in young mice (PS199). Intriguingly, this pattern was reversed in older animals which displayed increased S199 phosphorylation and decreased phospho-S202/T205, indicative of age-dependent tau modifications at these 


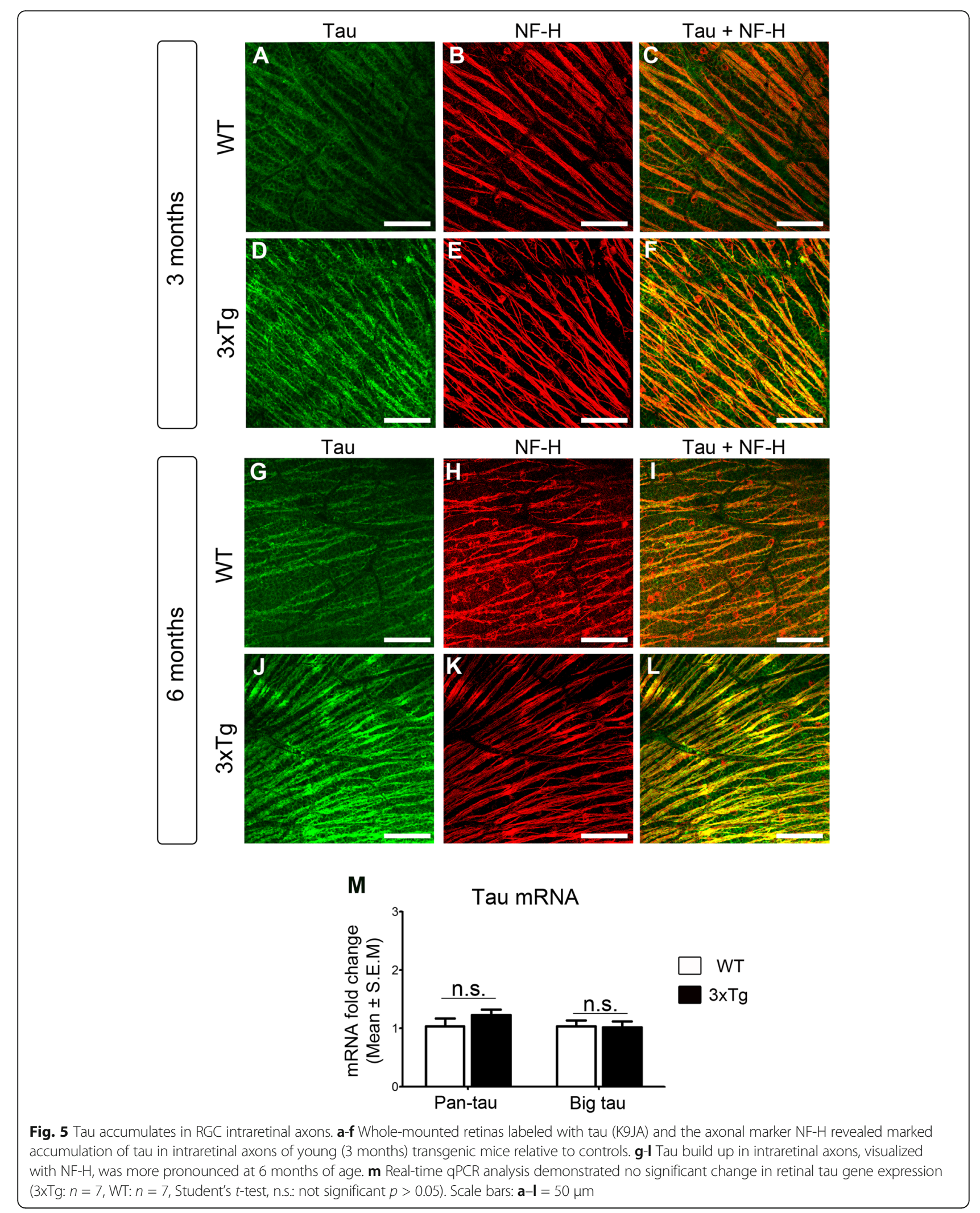




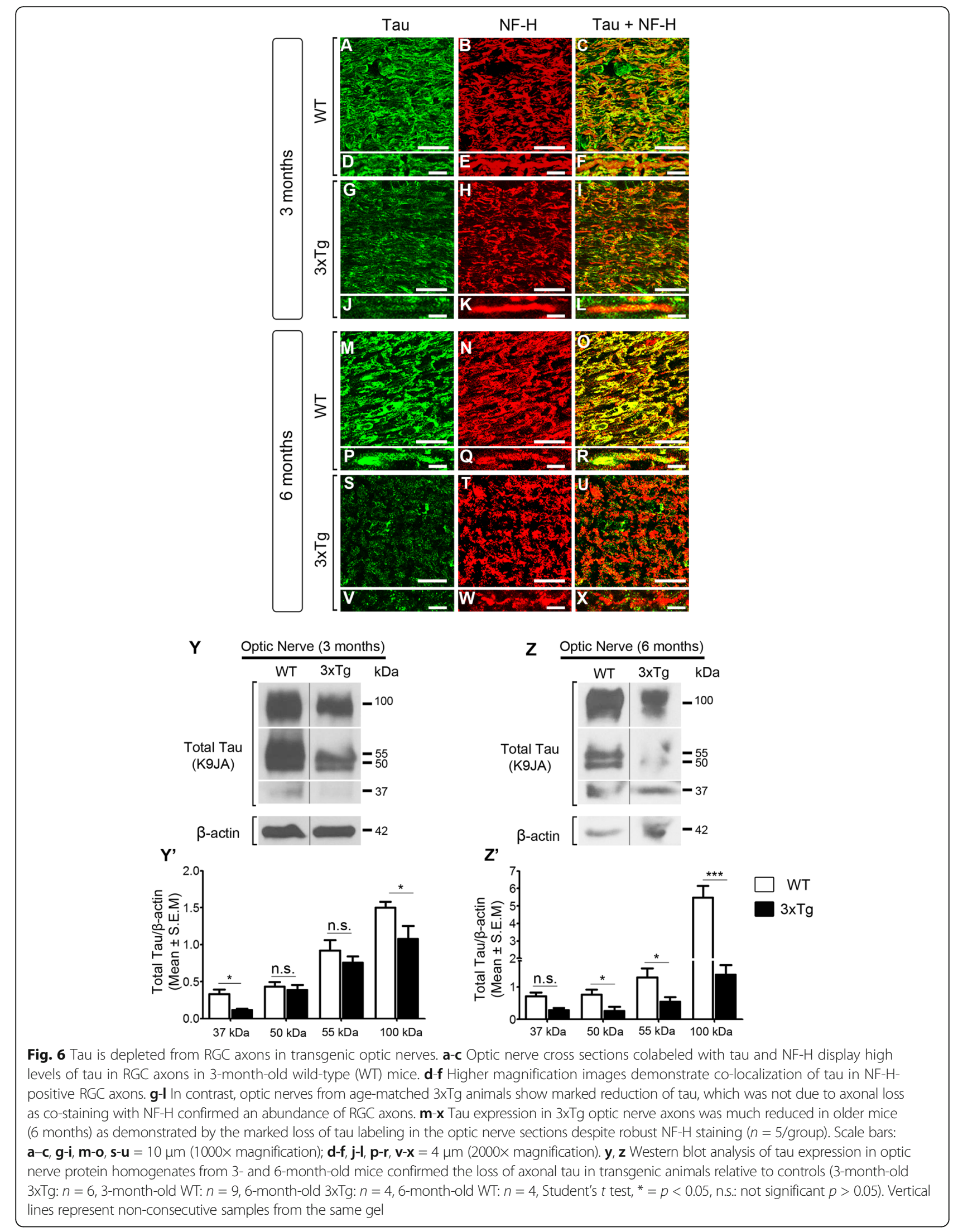




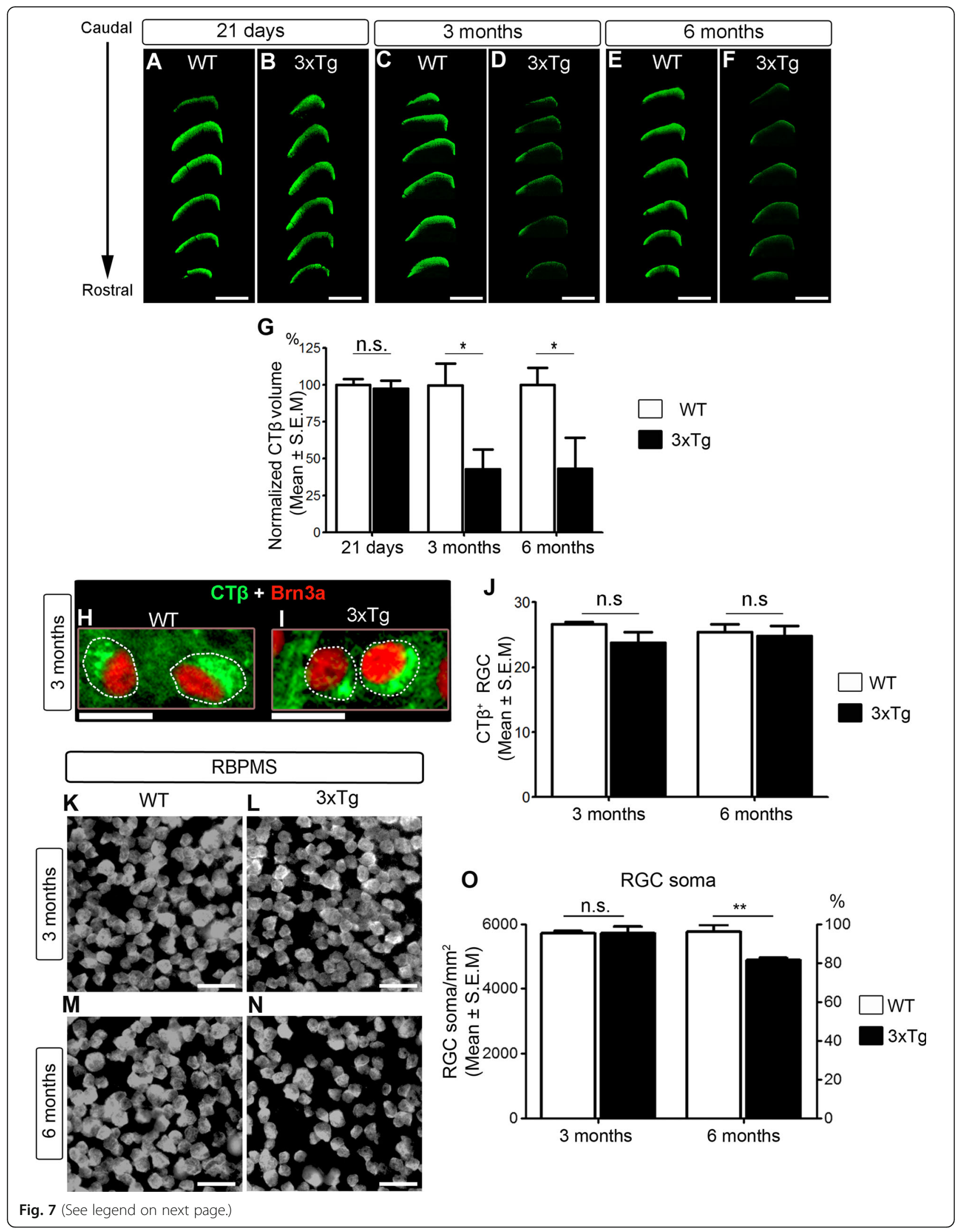


(See figure on previous page.)

Fig. 7 Anterograde transport impairment in 3xTg RGCs precedes neuronal death. a-f Unbiased stereological rostral to caudal sampling of the superior colliculus after CT $\beta$ injection showed no changes in CT $\beta$ labeling in 21-day-old wild-type or 3xTg mice. In contrast, a marked reduction of CT $\beta$ labeling was observed in both 3- and 6-month-old 3xTg mice relative to controls. $\mathbf{g}$ Quantification of the total CT $\beta$-positive region in the superior colliculus demonstrated a striking loss of anterograde transport in transgenic mice compared to age-matched wild-type (WT) controls (3-month-old 3xTg: $n=5$, 3-month-old WT: $n=3$, 6-month-old 3xTg: $n=5$, 6-month-old WT: $n=5$, Student's t-test, ${ }^{*}=p<0.05$ ). $\mathbf{h}$, i Co-labeling of CT (green) with the RGC-specific marker Brn3a (red) confirmed effective CT $\beta$ uptake by RGCs in both 3xTg and WT retinas. $\mathbf{j}$ Quantitative analysis confirmed that there was no difference in the number of CT $\beta$ - and Brn3a-positive RGCs between 3xTg and WT retina at 3 or 6 months of age (3-month-old 3xTg: $n=3$, 3-month-old WT: $n=3$, 6-month-old 3xTg: $n=3$, 6-month-old WT: $n=4$ ). $\mathbf{k}$-m Flat-mounted retinas labeled with the RGC-specific marker RBPMS were used to quantify RGC density (survival). o Quantitative analysis of RGC density demonstrated absence of cell death in 3-month-old 3xTg mice, while only a modest loss was observed in 6-month-old transgenic animals relative to age-matched WT controls (3-month-old 3xTg: $n=5$, 3-month-old WT: $n=6$, 6-month-old 3xTg: $n=5$, 6-month-old WT: $n=5$, Student's t-test, ${ }^{*} p<0.05$, n.s.: not significant $p>0.05$ ). Scale bars: $A-D=500 \mu m, F-G=25 \mu m, K-N=7.5 \mu m$

residues. Although tau hyperphosphorylation has received much attention, accumulating data indicate that oxidative stress, excitotoxicity and starvation induce tau hypophosphorylation [102-104]. Tau dephosphorylation has also been reported during ischemia, hypoxia and glucose deprivation in animal models and in human brain tissue [105-108], indicative of a potential pathological role. Of interest, the alterations in tau phosphorylation observed in 3xTg retinas were different from those we reported in a model of ocular hypertension

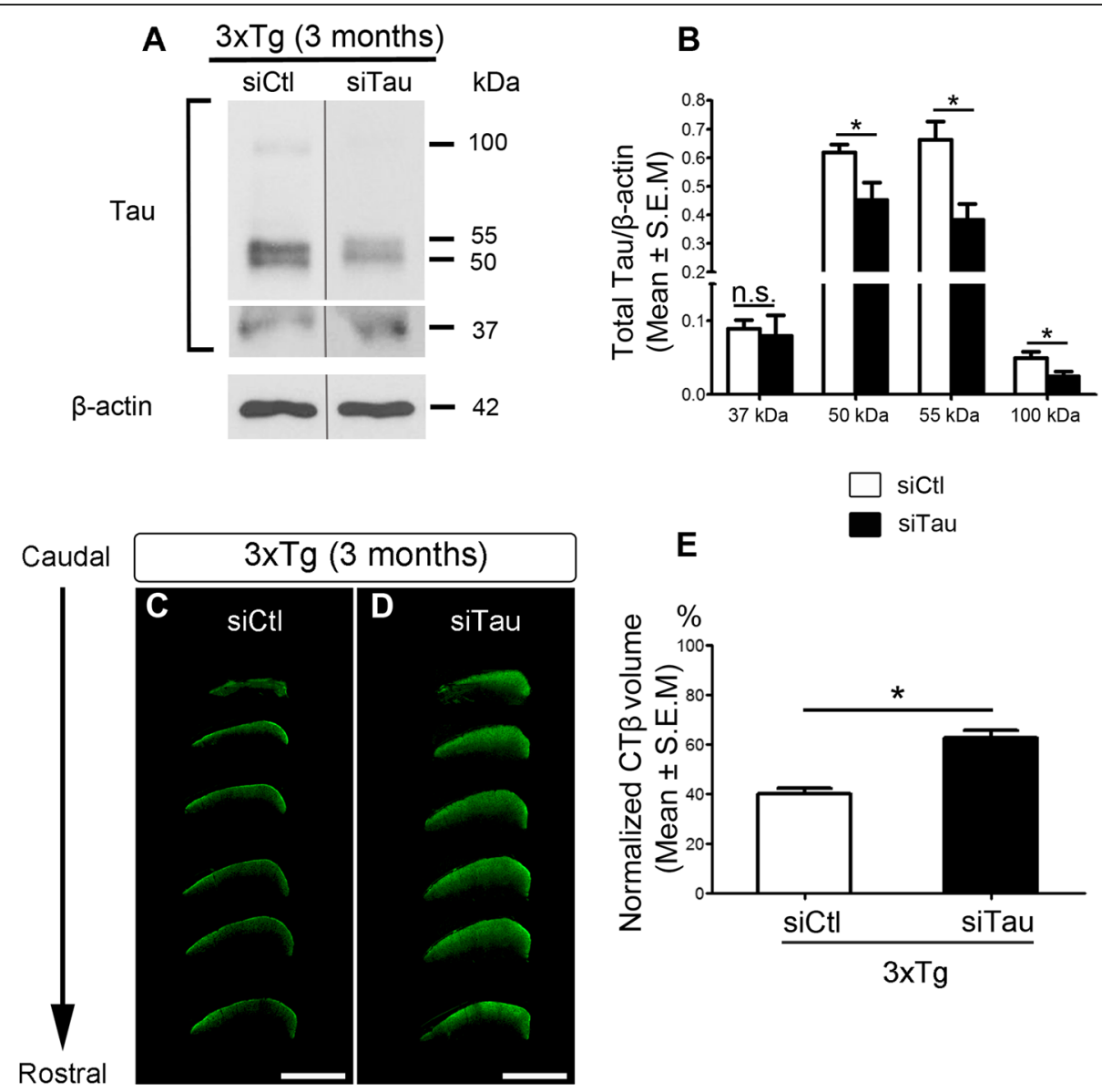

Fig. 8 siRNA-mediated tau deletion improves axonal transport. a, b Western blot analysis of retinal homogenates from transgenic eyes treated with short interference RNA (siRNA). Eyes injected with siRNA against tau (siTau) showed a significant reduction in tau protein (50-kDa, 55 k-Da, and $100 \mathrm{k}$-Da) while a control siRNA (siCtl) had no effect (siCtl: $n=3$; siTau: $n=3$; Student's $t$-test, ${ }^{*}=p<0.05$ ). $\mathbf{c}$, d Unbiased rostrocaudal stereological sampling of the superior colliculus after tracer injection shows increased CT $\beta$ in the brains of 3xTg mice that received siTau relative to siCt--treated control mice. e Quantitative analysis of the total $C T \beta$ volume shows a significant increase of anterograde transport (20\%) in siTau-treated mice compared to siCtl-treated controls (siTau: $n=5$, siCtl: $n=6$, Student's t-test, ${ }^{*}=p<0.05$ ). Scale bars: C, D $=500 \mu \mathrm{m}$ 
glaucoma in which S396/S404 residues were hyperphosphorylated, S199 hypophosphorylated, and S202/T205 remained unchanged [4]. Collectively, our observations demonstrate disease-specific changes in retinal tau phosphorylation on key residues.

Tau is an axonal-enriched protein and its abnormal localization to compartments other than the axon, such as soma and dendrites, strongly correlates with neuronal pathology and cognitive decline [109]. RGCs are highly polarized neurons: their soma, dendrites and initial nonmyelinated axonal segments are within the retina, whereas the distal myelinated axons are in the optic nerve outside the eye [110]. Our data demonstrate that tau accumulated in RGC dendrites and intraretinal axons, while it was depleted from optic nerve axons in $3 x \mathrm{Tg}$ mice. This abnormal tau distribution is consistent with pathological changes observed in diseases affecting RGCs such as glaucoma, in which tau accumulates in RGC soma and dendrites leading to neuronal death [4]. Despite the clear redistribution of tau from RGC axons to soma, there was no net increase of tau detected biochemically from 3 to 6 months of age. It is possible that the intracellular redistribution observed in RGCs does not faithfully reflect the global retinal changes detected by western blot analysis. We previously demonstrated that tau is present in retinal cells other than RGCs [4], and tau has also been shown to exist in the extracellular space [111], which could account for this discrepancy. Nonetheless, the pathological properties of tau do not stem only from its accumulation but also from post-translational modifications, most notably phosphorylation. Our data show that the phosphorylation pattern of tau changed dramatically at 6 months relative to younger mice, which might contribute to RGC dysfunction and death.

The lack of changes in tau mRNA levels ruled out transcriptional regulation as a mechanism for tau accumulation in $\mathrm{AD}$ retinas. In physiological conditions, tau protein is produced in the cell body and readily sorted to the axon [112], hence the mislocalization of tau in 3xTg RGCs points to the existence of alterations in the sorting mechanisms that control the normal distribution of tau in different neuronal compartments. Changes in tau phosphorylation might reduce its affinity for axonal microtubules and increase it for dendritic microtubules, as shown in cultured spinal cord neurons [113]. Alternatively, retinal tau accumulation might result from impaired degradation in proximal RGC compartments due to defective autophagy or proteasomal pathways and/or altered protein turn over $[114,115]$. Future work will be essential to establish the mechanisms driving tau accumulation and missorting in the visual system during the course of AD.

Tau is best known for its role in assembling and stabilizing axonal microtubule networks [116]. In vitro studies have demonstrated that tau can regulate axonal transport primarily by modulating the function of kinesin motor proteins, which mediate anterograde movement $[11,117,118]$. For example, tau overexpression in cultured cells dramatically impairs the anterograde transport of a variety of cargos [119-123]. Previous in vivo studies, however, have yielded controversial results with some reporting reduced anterograde transport in mice overexpressing tau while others showed little or no change [124-126]. Our data using СT $\beta$ accumulation in the brain, a readout of active microtubule-dependent transport [88], demonstrate early and substantial deficits in transport along RGC axons in 3xTg mice, which is consistent with previous findings in a model of frontotemporal dementia [47]. Importantly, axonal transport dysfunction was not the result of cell death because transport deficits were detected in young $3 \times \mathrm{xTg}$ mice prior to RGC loss.

To test whether tau accumulation in the retina contributed to axonal transport impairment, we used a siRNA strategy based on the ability to selectively attenuate tau, without completely inhibiting it, and our observation that siRNAs are readily taken up by RGCs when injected into the vitreous space [4, 98]. Although this siRNA approach only partially decreased tau levels in the retina, we observed an improvement of axonal transport in 3xTg RGCs (20\%) providing strong proof-ofprinciple for: 1) a detrimental role of tau accumulation on the regulation of anterograde axonal transport in vivo, and 2) early tau-dependent RGC dysfunction preceding overt neurodegeneration in AD. The decrease of tau burden in the retina appears to have a widespread beneficial effect on the overall health of RGCs leading to improvements in axonal transport and functionality. The mechanism by which pathological tau disrupts anterograde transport in RGCs is currently unknown, but might involve tau detachment and microtubule network destabilization or excessive binding of tau to microtubules resulting in the displacement of kinesin motors $[117,118,127]$. Independent of the mode of action, our findings provide the first demonstration that a global strategy to reduce retinal tau using siRNA is an effective approach to improve axonal transport and attenuate neuronal dysfunction in $\mathrm{AD}$.

\section{Conclusions}

Substantial visual deficits have been documented in Alzheimer's disease patients; however, the molecular basis of this impairment is poorly understood. This study reveals early and profound alterations in retinal tau including abnormal accumulation, phosphorylation, and missorting. These pathological changes cause substantial retinal neuron dysfunction and subsequent death, suggesting a prominent role for pathological tau 
in visual defects. The eye is the most accessible part of the CNS and the transparent ocular structures allow swift visualization of the retina. Retinal tau is a promising target to detect early pathological changes and to further understand fundamental mechanisms of neuronal damage in $\mathrm{AD}$ and tauopathies.

\section{Abbreviations}

3xTg: PS1(M146 V)APP(Swe)and tau(P301L) triple transgenic mice;

AD: Alzheimer's disease; CNS: central nervous system; CTß: cholera toxin $\beta$ subunit; PBS: phosphate buffer saline; qPCR: quantitative polymerase chain reaction; RBPMS: RNA-binding protein with multiple splicing; RGC: retinal ganglion cell; siRNA: short interference RNA

\section{Acknowledgements}

We thank Dr. Timothy E. Kennedy for helpful comments on the manuscript, and Dr. Peter Davies (Albert Einstein College of Medicine, Bronx, NY) for providing the PHF1, MC-1 and ALZ-50 antibodies.

\section{Funding}

This work was supported by grants from the Canadian Institutes of Health Research (CIHR) and Institut de Recherches Servier. CW is a CIHR New Investigator. ADP is a Chercheur National of Fonds de recherche QuébecSanté (FRQS).

\section{Availability of data and materials}

The datasets supporting the conclusions of this article are included within the article and its additional file.

\section{Authors' contributions}

$\mathrm{ADP}, \mathrm{MC}, \mathrm{CW}, \mathrm{CL}$ and FP designed the overall approach and experiments of the study. MC performed the biochemical and immunohistochemical experiments, axonal transport assays in siRNA-treated mice, carried out the statistical analysis of the data, and prepared all the figures. LAM carried out the anterograde axonal transport and CT $\beta$ uptake assays in transgenic mice and age-matched controls and revised the manuscript. NB performed the multiple intraocular injections in mice eyes for the siRNA-based experiments and revised the manuscript. FD and $\mathrm{HQ}$ collected all the retinal and brain samples used in the study and managed the mice colonies. LD and HQ performed the real-time PCR and revised the manuscript. MC and ADP interpreted the results and wrote the manuscript. FP and $C L$ gave critical input and comments on the manuscript. All authors read and approved the final manuscript

\section{Ethics approval}

All animal procedures were approved by the Centre de Recherche du Centre Hospitalier de l'Université de Montréal (CRCHUM) Animal Care Committee (approved protocol \#N14024ADPs) and were performed in compliance with the Canadian Council on Animal Care for the Use of Experimental Animals (http:// www.ccac.ca).

\section{Consent for publication}

All authors have given their consent for the publication of this study.

\section{Competing interests}

The authors declare no competing financial interest. FP and $\mathrm{CL}$ are employees of the Institut de Recherches Servier but do not have a financial interest in the work presented in the current manuscript.

\section{Publisher's Note}

Springer Nature remains neutral with regard to jurisdictional claims in published maps and institutional affiliations.

\section{Author details}

'Department of Neuroscience and Centre de recherche du centre hospitalier de l'Université de Montréal (CRCHUM), Université de Montréal, 900 Rue Saint-Denis, Tour Viger, Room R09.720, Montréal, QC H2X 0A9, Canada. ${ }^{2}$ Institut de Recherches Servier, 78290 Croissy-sur-Seine, France.
Received: 2 May 2017 Accepted: 31 July 2017

Published online: 03 August 2017

\section{References}

1. Cairns NJ, Bigio EH, Mackenzie IR, Neumann M, Lee VM, Hatanpaa KJ, White CL 3rd, Schneider JA, Grinberg LT, Halliday G, et al. Neuropathologic diagnostic and nosologic criteria for frontotemporal lobar degeneration: consensus of the consortium for Frontotemporal lobar degeneration. Acta Neuropathol. 2007:114:5-22.

2. Delacourte A, Defossez A. Alzheimer's disease: tau proteins, the promoting factors of microtubule assembly, are major components of paired helical filaments. J Neurol Sci. 1986;76:173-86.

3. Grundke-lqbal I, Iqbal K, Tung YC, Quinlan M, Wisniewski HM, Binder LI. Abnormal phosphorylation of the microtubule-associated protein tau (tau) in Alzheimer cytoskeletal pathology. Proc Natl Acad Sci U S A. 1986;83:4913-7.

4. Chiasseu M, Cueva Vargas JL, Destroismaisons L, Vande Velde C, Leclerc N, Di Polo A. Tau accumulation, altered phosphorylation, and missorting promote neurodegeneration in glaucoma. J Neurosci. 2016:36:5785-98.

5. Drewes G, Trinczek B, Illenberger S, Biernat J, Schmitt-Ulms G, Meyer HE, Mandelkow EM, Mandelkow E. Microtubule-associated protein/microtubule affinity-regulating kinase (p110mark): a novel protein kinase that regulates tau-microtubule interactions and dynamic instability by phosphorylation at the Alzheimer-specific site serine 262. J Biol Chem. 1995;270:7679-88.

6. Kimura T, Ono T, Takamatsu J, Yamamoto H, Ikegami K, Kondo A, Hasegawa M, Yasuolham, Miyamoto E, Miyakawa T. Sequential changes of tau-sitespecific phosphorylation during development of paired helical filaments. Dementia. 1996;7:177-181.

7. Mailliot C, Sergeant N, Bussiere T, Caillet-Boudin ML, Delacourte A, Buee L. Phosphorylation of specific sets of tau isoforms reflects different neurofibrillary degeneration processes. FEBS Lett. 1998;433:201-4.

8. Alonso AC, Grundke-lqbal I, lqbal K. Alzheimer's disease hyperphosphorylated tau sequesters normal tau into tangles of filaments and disassembles microtubules. Nat Med. 1996;2:783-7.

9. Braak H, Braak E. Staging of Alzheimer's disease-related neurofibrillary changes. Neurobiol Aging. 1995;16:271-84.

10. Feany MB, Mattiace LA, Dickson DW. Neuropathologic overlap of progressive supranuclear palsy, Pick's disease and corticobasal degeneration. J Neuropathol Exp Neurol. 1996:55:53-67.

11. Stamer K, Vogel R, Thies E, Mandelkow E, Mandelkow EM. Tau blocks traffic of organelles, neurofilaments, and APP vesicles in neurons and enhances oxidative stress. J Cell Biol. 2002;156:1051-63.

12. Kraemer BC, Zhang B, Leverenz JB, Thomas JH, Trojanowski JQ, Schellenberg GD. Neurodegeneration and defective neurotransmission in a Caenorhabditis Elegans model of tauopathy. Proc Natl Acad Sci U S A. 2003;100:9980-5.

13. Oddo S, Caccamo A, Shepherd JD, Murphy MP, Golde TE, Kayed R, Metherate R, Mattson MP, Akbari Y, LaFerla FM. Triple-transgenic model of Alzheimer's disease with plaques and tangles: intracellular Abeta and synaptic dysfunction. Neuron. 2003:39:409-21.

14. Ballatore C, Lee VM, Trojanowski JQ. Tau-mediated neurodegeneration in Alzheimer's disease and related disorders. Nat Rev Neurosci. 2007:8:663-72.

15. Gendreau KL, Hall GF. Tangles, toxicity, and tau secretion in AD - new approaches to a vexing problem. Front Neurol. 2013;4:160.

16. Carrillo MC, Dean RA, Nicolas F, Miller DS, Berman R, Khachaturian Z, Bain LJ, Schindler R, Knopman D, Alzheimer's Association Research R. Revisiting the framework of the National Institute on Aging-Alzheimer's Association diagnostic criteria. Alzheimers Dement. 2013;9:594-601.

17. Morsch R, Simon W, Coleman PD. Neurons may live for decades with neurofibrillary tangles. J Neuropathol Exp Neurol. 1999;58:188-97.

18. Masland RH. The neuronal organization of the retina. Neuron. 2012;76:266-80.

19. Javaid FZ, Brenton J, Guo L, Cordeiro MF. Visual and ocular manifestations of Alzheimer's disease and their use as biomarkers for diagnosis and progression. Front Neurol. 2016;7:55.

20. Gronin-Golomb A, Hof P. Vision in Alzheimer's disease, vol. 34. 1st ed. Switzerland: Karger; 2004.

21. Rizzo M, Anderson SW, Dawson J, Nawrot M. Vision and cognition in Alzheimer's disease. Neuropsychologia. 2000;38:1157-69.

22. Cronin-Golomb A. Heterogeneity of visual presentation in Alzheimer's disease. In: Gronin-Golomb A, Hof P, editors. Vision in Alzheimer's disease. Switzerland: Karger; 2004. p. 370-6. 
23. Blanks JC, Hinton DR, Sadun AA, Miller CA. Retinal ganglion cell degeneration in Alzheimer's disease. Brain Res. 1989;501:364-72.

24. Hinton DR, Sadun AA, Blanks JC, Miller CA. Optic-nerve degeneration in Alzheimer's disease. N Engl J Med. 1986;315:485-7.

25. Katz B, Rimmer S. Ophthalmoplegic migraine with superior ramus oculomotor paresis. J Clin Neuroophthalmol. 1989;9:181-3.

26. Jackson GR, Owsley C. Visual dysfunction, neurodegenerative diseases, and aging. Neurol Clin. 2003;21:709-28.

27. Lee AG, Martin CO. Neuro-ophthalmic findings in the visual variant of Alzheimer's disease. Ophthalmology. 2004;111:376-81.

28. Uhlmann RF, Larson EB, Koepsell TD, Rees TS, Duckert LG. Visual impairment and cognitive dysfunction in Alzheimer's disease. J Gen Intern Med. 1991;6:126-32.

29. Cronin-Golomb A, Corkin S, Growdon JH. Visual dysfunction predicts cognitive deficits in Alzheimer's disease. Optom Vis Sci. 1995;72:168-76.

30. Cronin-Golomb A, Gilmore GC, Neargarder S, Morrison SR, Laudate TM. Enhanced stimulus strength improves visual cognition in aging and Alzheimer's disease. Cortex. 2007;43:952-66.

31. Mendola JD, Cronin-Golomb A, Corkin S, Growdon JH. Prevalence of visual deficits in Alzheimer's disease. Optom Vis Sci. 1995;72:155-67.

32. Mendola J, Cronin-Golomb A, Corkin S, Growdon J. Prevalence of visual deficits in Alzheimer's disease. Optom Vis Sci. 1995;72:155-67.

33. Mapstone $M$, Steffenella T, Duffy C. A visuospatial variant of mild cognitive impairment: getting lost between aging and AD. Neurology. 2003:802-8.

34. Trick $G$, Trick $L$, Morris $P$, Wolf M. Visual field loss in senile dementia of the Alzheimer's type. Neurology. 1995;45:68-74.

35. Paquet C, Boissonnot M, Roger F, Dighiero P, Gil R, Hugon J. Abnormal retinal thickness in patients with mild cognitive impairment and Alzheimer's disease. Neurosci Lett. 2007;420:97-9.

36. Kesler A, Vakhapova V, Korczyn AD, Naftaliev E, Neudorfer M. Retinal thickness in patients with mild cognitive impairment and Alzheimer's disease. Clin Neurol Neurosurg. 2011;113:523-6.

37. Blanks JC, Torigoe Y, Hinton DR, Blanks RH. Retinal pathology in Alzheimer's disease. I. Ganglion cell loss in foveal/parafoveal retina. Neurobiol Aging. 1996;17:377-84

38. Blanks JC, Schmidt SY, Torigoe Y, Porrello KV, Hinton DR, Blanks RH. Retinal pathology in Alzheimer's disease. II. Regional neuron loss and glial changes in GCL. Neurobiol Aging. 1996;17:385-95.

39. Parisi V, Restuccia R, Fattapposta F, Mina C, Bucci MG, Pierelli F. Morphological and functional retinal impairment in Alzheimer's disease patients. Clin Neurophysiol. 2001;112:1860-7.

40. Cheung CY, Ong YT, Ikram MK, Ong SY, Li X, Hilal S, Catindig JA, Venketasubramanian N, Yap P, Seow D, et al. Microvascular network alterations in the retina of patients with Alzheimer's disease. Alzheimers Dement. 2014;10:135-42.

41. Williams MA, McGowan AJ, Cardwell CR, Cheung CY, Craig D, Passmore P, Silvestri G, Maxwell AP, McKay GJ. Retinal microvascular network attenuation in Alzheimer's disease. Alzheimers Dement (Amst). 2015;1:229-35.

42. Gupta VK, Chitranshi N, Gupta VB, Golzan M, Dheer Y, Wall RV, Georgevsky $D$, King AE, Vickers JC, Chung R, Graham S. Amyloid beta accumulation and inner retinal degenerative changes in Alzheimer's disease transgenic mouse. Neurosci Lett. 2016;623:52-6.

43. Ning A, Cui J, To E, Ashe KH, Matsubara J. Amyloid-beta deposits lead to retinal degeneration in a mouse model of Alzheimer disease. Invest Ophthalmol Vis Sci. 2008:49:5136-43.

44. Liu B, Rasool S, Yang Z, Glabe CG, Schreiber SS, Ge J, Tan Z. Amyloidpeptide vaccinations reduce $\beta$-amyloid plaques but exacerbate vascular deposition and inflammation in the retina of Alzheimer's transgenic mice. Am J Pathol. 2009;175:2099-110.

45. Gasparini L, Crowther RA, Martin KR, Berg N, Coleman M, Goedert M, Spillantini MG. Tau inclusions in retinal ganglion cells of human P301S tau transgenic mice: effects on axonal viability. Neurobiol Aging. 2011;32:419-33.

46. Schon C, Hoffmann NA, Ochs SM, Burgold S, Filser S, Steinbach S, Seeliger MW, Arzberger T, Goedert M, Kretzschmar HA, et al. Long-term in vivo imaging of fibrillar tau in the retina of P301S transgenic mice. PLoS One. 2012;7:e53547

47. Bull ND, Guidi A, Goedert M, Martin KR, Spillantini MG. Reduced axonal transport and increased excitotoxic retinal ganglion cell degeneration in mice transgenic for human mutant P301S tau. PLoS One. 2012;7:e34724.

48. Mazzaro N, Barini E, Spillantini MG, Goedert M, Medini P, Gasparini L. Taudriven neuronal and neurotrophic dysfunction in a mouse model of early tauopathy. J Neurosci. 2016;36:2086-100.
49. Elder GA, Gama Sosa MA, De Gasperi R. Transgenic mouse models of Alzheimer's disease. Mt Sinai J Med. 2010;77:69-81.

50. Stover KR, Campbell MA, Van Winssen CM, Brown RE. Early detection of cognitive deficits in the 3xTg-AD mouse model of Alzheimer's disease. Behav Brain Res. 2015;289:29-38.

51. Oddo S, Caccamo A, Kitazawa M, Tseng BP, LaFerla FM. Amyloid deposition precedes tangle formation in a triple transgenic model of Alzheimer's disease. Neurobiol Aging. 2003;24:1063-70.

52. Carroll JC, Rosario ER, Kreimer S, Villamagna A, Gentzschein E, Stanczyk FZ, Pike CJ. Sex differences in beta-amyloid accumulation in 3xTg-AD mice: role of neonatal sex steroid hormone exposure. Brain Res. 2010;1366:233-45.

53. Planel E, Miyasaka T, Launey T, Chui D-H, Tanemura K, Sato S, Murayama O, Ishiguro K, Tatebayashi Y, Takashima A. Alterations in glucose metabolism induce hypothermia leading to tau hyperphosphorylation through differential inhibition of kinase and phosphatase activities: implications for Alzheimer's disease. J Neurosci. 2004;24:2401.

54. Cueva Vargas JL, Belforte N, Di Polo A. The glial cell modulator ibudilast attenuates neuroinflammation and enhances retinal ganglion cell viability in glaucoma through protein kinase a signaling. Neurobiol Dis. 2016;93:156-71.

55. Crish SD, Sappington RM, Inman DM, Horner PJ, Calkins DJ. Distal axonopathy with structural persistence in glaucomatous neurodegeneration. Proc Natl Acad Sci U S A. 2010;107:5196-201.

56. Angelucci A, Clasca F, Sur M. Anterograde axonal tracing with the subunit B of cholera toxin: a highly sensitive immunohistochemical protocol for revealing fine axonal morphology in adult and neonatal brains. J Neurosci Methods. 1996;65:101-12.

57. Aviles-Trigueros M, Mayor-Torroglosa S, Garcia-Aviles A, Lafuente MP, Rodriguez ME, Miralles de Imperial J, Villegas-Perez MP, Vidal-Sanz M. Transient ischemia of the retina results in massive degeneration of the retinotectal projection: long-term neuroprotection with brimonidine. Exp Neurol. 2003;184:767-77.

58. Ito YA, Belforte N, Cueva Vargas JL, Di Polo A. A magnetic microbead occlusion model to induce ocular hypertension-dependent glaucoma in mice. J Vis Exp. 2016:53731

59. Mouton PR. Principles and practices of unbiased stereology: an introduction for bioscientists. Baltimore, Maryland: The Johns Hopkins University Press; 2002.

60. Billings LM, Oddo S, Green KN, McGaugh JL, LaFerla FM. Intraneuronal Abeta causes the onset of early Alzheimer's disease-related cognitive deficits in transgenic mice. Neuron. 2005;45:675-88.

61. Plouffe V, Mohamed NV, Rivest-McGraw J, Bertrand J, Lauzon M, Leclerc N. Hyperphosphorylation and cleavage at D421 enhance tau secretion. PLoS One. 2012;7:e36873.

62. Biernat J, Wu YZ, Timm T, Zheng-Fischhofer Q, Mandelkow E, Meijer L, Mandelkow EM. Protein kinase MARK/PAR-1 is required for neurite outgrowth and establishment of neuronal polarity. Mol Biol Cell. 2002; 13:4013-28.

63. Oblinger MM, Argasinski A, Wong J, Kosik KS. Tau gene expression in rat sensory neurons during development and regeneration. J Neurosci. 1991:11:2453-9.

64. Goedert M, Spillantini MG, Crowther RA. Cloning of a big tau microtubuleassociated protein characteristic of the peripheral nervous system. Proc Nat Acad Sci U S A. 1992;89:1983-7.

65. Boyne $\sqcup$, Tessler A, Murray M, Fischer I. Distribution of big tau in the central nervous system of the adult and developing rat. J Comp Neurol. 1995;358:279-93.

66. Buee L, Bussiere T, Buee-Scherrer V, Delacourte A, Hof PR. Tau protein isoforms, phosphorylation and role in neurodegenerative disorders. Brain Res Brain Res Rev. 2000;33:95-130.

67. Kuret J, Chirita CN, Congdon EE, Kannanayakal T, Li G, Necula M, Yin H, Zhong Q. Pathways of tau fibrillization. Biochim Biophys Acta. 2005; 1739:167-78.

68. Porzig R, Singer $D$, Hoffmann R. Epitope mapping of mAbs AT8 and Tau5 directed against hyperphosphorylated regions of the human tau protein. Biochem Biophys Res Commun. 2007;358:644-9.

69. Biernat J, Mandelkow EM, Schroter C, Lichtenberg-Kraag B, Steiner B, Berling B, Meyer H, Mercken M, Vandermeeren A, Goedert M, et al. The switch of tau protein to an Alzheimer-like state includes the phosphorylation of two serine-proline motifs upstream of the microtubule binding region. EMBO J. 1992;11:1593-7.

70. Dong DW, Zhang YS, Yang WY, Wang-Qin RQ, Xu AD, Ruan YW. Hyperphosphorylation of tau protein in the ipsilateral thalamus after focal cortical infarction in rats. Brain Res. 2014;1543:280-9. 
71. Greenberg SG, Davies P, Schein JD, Binder LI. Hydrofluoric acid-treated tau PHF proteins display the same biochemical properties as normal tau. J Biol Chem. 1992;267:564-9.

72. Otvos L Jr, Feiner L, Lang E, Szendrei Gl, Goedert M, Lee VM. Monoclonal antibody PHF-1 recognizes tau protein phosphorylated at serine residues 396 and 404. J Neurosci Res. 1994;39:669-73.

73. Augustinack JC, Schneider A, Mandelkow EM, Hyman BT. Specific tau phosphorylation sites correlate with severity of neuronal cytopathology in Alzheimer's disease. Acta Neuropathol. 2002;103:26-35.

74. Binder LI, Guillozet-Bongaarts AL, Garcia-Sierra F, Berry RW. Tau, tangles, and Alzheimer's disease. Biochim Biophys Acta. 2005;1739:216-23.

75. Garcia-Sierra F, Ghoshal N, Quinn B, Berry RW, Binder LI. Conformational changes and truncation of tau protein during tangle evolution in Alzheimer's disease. J Alzheimers Dis. 2003;5:65-77.

76. Carmel G, Mager EM, Binder LI, Kuret J. The structural basis of monoclonal antibody Alz50's selectivity for Alzheimer's disease pathology. J Biol Chem. 1996;271:32789-95.

77. Jicha GA, Bowser R, Kazam IG, Davies P. Alz-50 and MC-1, a new monoclonal antibody raised to paired helical filaments, recognize conformational epitopes on recombinant tau. J Neurosci Res. 1997;48:128-32.

78. Ho WL, Leung Y, Cheng SS, Lok CK, Ho YS, Baum L, Yang X, Chiu K, Chang $\mathrm{RC}$. Investigating degeneration of the retina in young and aged tau P301L mice. Life Sci. 2015;124:16-23.

79. Yin Y, Cui Q, Li Y, Irwin N, Fischer D, Harvey AR, Benowitz LI. Macrophagederived factors stimulate optic nerve regeneration. J Neurosci. 2003;23:2284-93.

80. Cui Q, Yip HK, Zhao RC, So KF, Harvey AR. Intraocular elevation of cyclic AMP potentiates ciliary neurotrophic factor-induced regeneration of adult rat retinal ganglion cell axons. Mol Cell Neurosci. 2003;22:49-61.

81. Kwong JM, Caprioli J, Piri N. RNA binding protein with multiple splicing: a new marker for retinal ganglion cells. Invest Ophthalmol Vis Sci. 2010;51: 1052-8.

82. Rodriguez AR, de Sevilla Muller LP, Brecha NC. The RNA binding protein RBPMS is a selective marker of ganglion cells in the mammalian retina. J Comp Neurol. 2014;522:1411-43.

83. Migheli A, Butler M, Brown K, Shelanski M. Light and electron microscope localization of the microtubule-associated tau protein in rat brain. $J$ Neurosci. 1988;8:1846-51.

84. Ballatore C, Lee VMY, Trojanowski JQ. Tau-mediated neurodegeneration in Alzheimer's disease and related disorders. Nat Rev Neurosci. 2007;8:663-72.

85. Dräger UC. Autoradiography of tritiated proline and fucose transported transneuronally from the eye to the visual cortex in pigmented and albino mice. Brain Res. 1974;82:284-92.

86. Hofbauer A, Dräger UC. Depth segregation of retinal ganglion cells projecting to mouse superior colliculus. J Comp Neurol. 1985;234:465-74.

87. Provencio I, Cooper HM, Foster RG. Retinal projections in mice with inherited retinal degeneration: implications for circadian photoentrainment. J Comp Neurol. 1998;395:417-39.

88. Abbott CJ, Choe TE, Lusardi TA, Burgoyne CF, Wang L, Fortune B. Imaging axonal transport in the rat visual pathway. Biomed Opt Express. 2013;4:364-86.

89. Wan X-CS, Trojanowski JQ, Gonatas JO. Cholera toxin and wheat germ agglutinin conjugates as neuroanatomical probes: their uptake and clearance, transganglionic and retrograde transport and sensitivity. Brain Res. 1982;243:215-24.

90. Luppi $\mathrm{P}-\mathrm{H}$, Fort $\mathrm{P}$, Jouvet $\mathrm{M}$. Iontophoretic application of unconjugated cholera toxin B subunit (CTb) combined with immunohistochemistry of neurochemical substances: a method for transmitter identification of retrogradely labeled neurons. Brain Res. 1990;534:209-24.

91. Wu CC, Russell RM, Karten HJ. The transport rate of cholera toxin B subunit in the retinofugal pathways of the chick. Neuroscience. 1999;92:665-76.

92. Wu CC, Russell RM, Nguyen RT, Karten HJ. Tracing developing pathways in the brain: a comparison of carbocyanine dyes and cholera toxin b subunit. Neuroscience. 2003;117:831-45

93. Fleming MD, Benca RM, Behan M. Retinal projections to the subcortical visual system in congenic albino and pigmented rats. Neuroscience. 2006; 143:895-904.

94. Rivera N, Lugo N. Four retinal ganglion cell types that project to the superior colliculus in the thirteen-lined ground squirrel (Spermophilus Tridecemlineatus). J Comp Neurol. 1998;396:105-20.

95. Schwab ME, Thoenen $\mathrm{H}$. Retrograde axonal and transsynaptic transport of macromolecules: physiological and pathophysiological importance. Agents Actions. 1977;7:361-8.
96. Mikkelsen JD. Visualization of efferent retinal projections by immunohistochemical identification of cholera toxin subunit B. Brain Res Bull. 1992;28:619-23.

97. Nadal-Nicolas FM, Jimenez-Lopez M, Sobrado-Calvo P, Nieto-Lopez L, Canovas-Martinez I, Salinas-Navarro M, Vidal-Sanz M, Agudo M. Brn3a as a marker of retinal ganglion cells: qualitative and quantitative time course studies in naive and optic nerve-injured retinas. Invest Ophthalmol Vis Sci. 2009;50:3860-8.

98. Wilson AM, Morquette B, Abdouh M, Unsain N, Barker PA, Feinstein E, Bernier G, Di Polo A. ASPP1/2 regulate p53-dependent death of retinal ganglion cells through PUMA and Fas/CD95 activation in vivo. J Neurosci. 2013;33:2205.

99. Lee VM, Goedert M, Trojanowski JQ. Neurodegenerative tauopathies. Annu Rev Neurosci. 2001;24:1121-59.

100. Iqbal K, Alonso Adel C, Chen S, Chohan MO, El-Akkad E, Gong CX, Khatoon S, Li B, Liu F, Rahman A, et al. Tau pathology in Alzheimer disease and other tauopathies. Biochim Biophys Acta. 2005;1739:198-210.

101. Hanger DP, Anderton BH, Noble W. Tau phosphorylation: the therapeutic challenge for neurodegenerative disease. Trends Mol Med. 2009;15:112-9.

102. Davis DR, Anderton BH, Brion J-P, Reynolds CH, Hanger DP. Oxidative stress induces dephosphorylation of $\mathrm{\tau}$ in rat brain primary neuronal cultures. $J$ Neurochem. 1997;68:1590-7

103. Kuszczyk M, Gordon-Krajcer W, Lazarewicz JW. Homocysteine-induced acute excitotoxicity in cerebellar granule cells in vitro is accompanied by PP2Amediated dephosphorylation of tau. Neurochem Int. 2009;55:174-80.

104. Mohamed N-V, Plouffe V, Rémillard-Labrosse G, Planel E, Leclerc N. Starvation and inhibition of lysosomal function increased tau secretion by primary cortical neurons. Sci Rep. 2014;4:5715.

105. Burkhart KK, Beard DC, Lehman RAW, Billingsley ML. Alterations in tau phosphorylation in rat and human neocortical brain slices following hypoxia and glucose deprivation. Exp Neurol. 1998;154:464-72.

106. Mailliot C, Podevin-Dimster V, Rosenthal R, Sergeant N, Delacourte A, Fiskum G, Buée L. Rapid tau protein dephosphorylation and differential rephosphorylation during cardiac arrest-induced cerebral ischemia and reperfusion. J Cereb Blood Flow Metab. 2000;20:543-9.

107. Shackelford DA, Nelson KE. Changes in phosphorylation of $\tau$ during ischemia and reperfusion in the rabbit spinal cord. J Neurochem. 1996;66:286-95.

108. Shackelford D, Yeh R. Dephosphorylation of tau during transient forebrain ischemia in the rat. Mol Chem Neuropathol. 1998;34:103-20.

109. Zempel H, Mandelkow E. Lost after translation: missorting of tau protein and consequences for Alzheimer disease. Trends Neurosci. 2014;37:721-32.

110. Calkins DJ. Critical pathogenic events underlying progression of neurodegeneration in glaucoma. Prog Retin Eye Res. 2012;31:702-19.

111. Avila J, Simón D, Díaz-Hernández M, Pintor J, Hernández F. Sources of extracellular tau and its signaling. J Alzheimers Dis. 2014:40:7-15.

112. Scholz T, Mandelkow E. Transport and diffusion of tau protein in neurons. Cell Mol Life Sci. 2014;71:3139-50.

113. Kanai $Y$, Hirokawa N. Sorting mechanisms of tau and MAP2 in neurons: suppressed axonal transit of MAP2 and locally regulated microtubule binding. Neuron. 1995;14:421-32.

114. Wang Y, Mandelkow E. Degradation of tau protein by autophagy and proteasomal pathways. Biochem Soc Trans. 2012;40:644.

115. Li X, Kumar Y, Zempel H, Mandelkow EM, Biernat J, Mandelkow E. Nove diffusion barrier for axonal retention of tau in neurons and its failure in neurodegeneration. EMBO J. 2011;30:4825-37.

116. Weingarten MD, Lockwood AH, Hwo SY, Kirschner MW. A protein factor essential for microtubule assembly. Proc Natl Acad Sci U S A. 1975;72:1858-62.

117. Dixit R, Ross JL, Goldman YE, Holzbaur ELF. Differential regulation of dynein and kinesin motor proteins by tau. Science. 2008;319:1086-9.

118. Vershinin M, Carter BC, Razafsky DS, King SJ, Gross SP. Multiple-motor based transport and its regulation by tau. Proc Natl Acad Sci U S A. 2007;104:87-92.

119. Ebneth A, Godemann R, Stamer K, Illenberger S, Trinczek B, Mandelkow E. Overexpression of tau protein inhibits kinesin-dependent trafficking of vesicles, mitochondria, and endoplasmic reticulum: implications for Alzheimer's disease. J Cell Biol. 1998;143:777-94.

120. Mandelkow E-M, Thies E, Trinczek B, Biernat J. MARK/PAR1 kinase is a regulator of microtubule-dependent transport in axons. J Cell Biol. 2004;167:99-110.

121. Dubey M, Chaudhury P, Kabiru H, Shea T. Tau inhibits anterograde axonal transport and perturbs stability in growing axonal neurites in part by displacing kinesin cargo: neurofilaments attenuate tau-mediated neurite instability. Cell Motil Cytoskeleton. 2008;65:89-99. 
122. Stoothoff W, Jones P, Spires Jones T, Joyner D, Chhabra E, Bercury K, Fan Z, Xie $\mathrm{H}$, Bacskai B, Edd J, et al. Differential effect of three-repeat and four-repeat tau on mitochondrial axonal transport. J Neurochem. 2009;111:417-27.

123. Thies E, Mandelkow E-M. Missorting of tau in neurons causes degeneration of synapses that can be rescued by the kinase MARK2/par-1. J Neurosci. 2007;27:2896-907.

124. Ishihara T, Hong M, Zhang B, Nakagawa Y, Lee MK, Trojanowski JQ, Lee VM. Age-dependent emergence and progression of a tauopathy in transgenic mice overexpressing the shortest human tau isoform. Neuron. 1999;24:751-62.

125. Zhang B, Maiti A, Shively S, Lakhani F, McDonald Jones G, Bruce J, Lee E, Xie $\mathrm{S}$, Joyce $\mathrm{S}$, Li C, et al. Microtubule-binding drugs offset tau sequestration by stabilizing microtubules and reversing fast axonal transport deficits in a tauopathy model. Proc Natl Acad Sci U S A. 2005;102:227-31.

126. Yuan A, Kumar A, Peterhoff C, Duff K, Nixon R. Axonal transport rates in vivo are unaffected by tau deletion or overexpression in mice. Neurosci. 2008;28:1682-7.

127. Seitz A, Kojima H, Oiwa K, Mandelkow E-M, Song Y-H. Single-molecule investigation of the interference between kinesin, tau and MAP2C. EMBO J. 2002;21:4896-905

\section{Submit your next manuscript to BioMed Central} and we will help you at every step:

- We accept pre-submission inquiries

- Our selector tool helps you to find the most relevant journal

- We provide round the clock customer support

- Convenient online submission

- Thorough peer review

- Inclusion in PubMed and all major indexing services

- Maximum visibility for your research

Submit your manuscript at www.biomedcentral.com/submit 